\title{
Article \\ Digitalizing Maritime Containers Shipping Companies: Impacts on Their Processes
}

\author{
Pedro-Luis Sanchez-Gonzalez *(D), David Díaz-Gutiérrez and Luis R. Núñez-Rivas
}

check for updates

Citation: Sanchez-Gonzalez, P.-L.; Díaz-Gutiérrez, D.; Núñez-Rivas, L.R. Digitalizing Maritime Containers Shipping Companies: Impacts on Their Processes. Appl. Sci. 2022, 12, 2532. https://doi.org/10.3390/ app12052532

Academic Editor: Vicente Julian

Received: 4 February 2022

Accepted: 26 February 2022

Published: 28 February 2022

Publisher's Note: MDPI stays neutral with regard to jurisdictional claims in published maps and institutional affiliations.

Copyright: (c) 2022 by the authors. Licensee MDPI, Basel, Switzerland. This article is an open access article distributed under the terms and conditions of the Creative Commons Attribution (CC BY) license (https:// creativecommons.org/licenses/by/ $4.0 /)$.
Escuela Técnica Superior de Ingenieros Navales, Universidad Politécnica de Madrid (UPM), Av. Arco de la Victoria, 4, 28040 Madrid, Spain; david.diaz@upm.es (D.D.-G.); luisramon.nunez@upm.es (L.R.N.-R.)

* Correspondence: pl.sanchez@alumnos.upm.es

\begin{abstract}
Key analysts are emphasizing the importance of the digitalization especially of the supply chain. This work aims to improve maritime shipping companies by introducing digitalization in their operations. This objective is achieved analyzing the impact of maritime container shipping companies' digitalization. This analysis requires as input the Business Process Model (BPMo) and an inventory of digital applications to verify how the BPMo changes when deploying the applications, define the prerequisites necessary for this deployment, and identify the key performance indicators (KPIs) to track it. The impact of the deployment of the applications has been quantified by using four performance dimensions: Costs, Time, Quality, and Flexibility. The results show that the impacts are different per application, with changes in the processes, the addition of new ones, and the decommissioning of others. The impact of digitalization is high when trying to deploy all the applications at the same time. Companies can leverage this work, which requires reviewing the documented impacts in their processes and the applications' prerequisites as well as updating their existing balanced scorecard, incorporating the application's KPIs. A list of 10 applications has been identified as "quick wins"; then, applications can be the starting point for digitalizing a company.
\end{abstract}

Keywords: digitalization; BPM; business process model; artificial intelligence; big data; virtual reality; internet of things; cloud computing; digital security; additive engineering

\section{Introduction}

Maritime transportation defied the COVID-19 disruption, laying the foundations for a transformation in global supply chains [1]. Maritime shipping companies form the backbone of maritime transportation; therefore, they have been forced to changes to follow the global chain changes.

In this context, the key analysts are emphasizing the importance of the digitalization especially of the supply chain, with high investments in artificial intelligence, real-time transportation visibility, etc. [2]. Given its relevance and their intermodal global operations, maritime transportation industry digitalization is key for the supply chain's digitalization.

Digitalization in the maritime transportation industry is being studied these days following different streams: Munim et al. focused on big data and artificial intelligence [3]; Plaza-Hernández studied the integration of IoT technologies in the industry [4]; Kapidani et al. looked at the industry digitalization from a sustainability point of view [5]; Kapnissis et al. investigated blockchain adoption in the industry [6]; Tijan et al. reviewed the drivers, success factors, and barriers to digital transformation in the maritime transport sector [7]. These articles are just a few examples that illustrate the relevance of digitalization research in the maritime transportation industry.

The research from the team of the present paper published in 2019 in Sensors (ISSN 1424-8220) showed that when looking at the three different industrial sectors that compose the maritime transportation industry (ship design and shipbuilding; shipping; and ports), its digitalization is moving at different speeds in the different domains and industrial sectors defined in the aforementioned Sensors paper: 
- Autonomous vehicles and robotics (hereafter, robotics).

- Artificial intelligence (AI).

- Big data.

- Virtual, augmented, and mixed reality (VR).

- The internet of things (IoT).

- Cloud and edge computing (hereafter, the cloud).

- Digital security.

- Three-dimensional (3D) printing and additive engineering (3DP).

The size of the maritime transportation industry makes it necessary to focus on one of their industrial sectors; therefore, this work is limited to shipping.

Any change to the operations of maritime shipping companies requires understanding of how they operate. Business Process Management (BPM) is the science that monitors how work is performed in an organization in order to ensure consistent outcomes and to take advantage of opportunities for improvement [8]; this makes BPM an optimal technique for understanding maritime shipping companies' operations.

Few published works make use of BPM for analyzing the maritime transportation sector. Lyridis et al. [9] made use of BPM to optimize operations of a shipping company for one specific route. Elbert et al. [10] resorted to BPM for ports optimization, thereby analyzing the chains taking place at ports when ships arrive or depart and the interactions with ground organizations. Cimino et al. [11] also relied on BPM for analyzing the impact of Information and Communication Technology (ICT) for ports optimization. Finally, Nikitakos et al. [12] partially used BPM in part to evaluate ICTs in the Greek-owned shipping sector.

The research being presented in this article aims to improve maritime shipping companies by introducing digitalization in their operations while being aware that the implementation of a successful business process model does not automatically bring about the same benefits for all companies [13] but rather is a starting point for understanding the problems. Given the importance of maritime container shipping companies for the maritime transportation industry, this research focuses on these companies. Since there are different types of maritime container shipping companies, those used in this study are companies that have their own fleet of vessels used both nautically and commercially by the company.

The contributions of this work are as follows:

1. To contribute to the digitalization of the industry via the analysis of the impacts of digitalizing the aforementioned process model;

2. To generate the key performance indicators (KPIs) that will allow a phased approach for the deployment of the processes' digitalization;

3. To identify a list of "quick wins": applications that given their optimal results on the analysis could be considered as the starting point for digitalizing a company.

This work is divided into the following sections: Section 2 describes the methodology used in the study; Section 3 includes the results of the impact of maritime container shipping companies processes' digitalization as well as its analysis and discussion; and finally, Section 4, summarizes the conclusions.

\section{Approach and Methodology}

Since the hypothesis that needs to be proved is that the impacts of maritime containers shipping companies' digitalization is different per application and that these applications can be grouped or clustered according to their impact in the company's operations, the first step was performing an impact analysis. The impact analysis performed in this work required two inputs: the maritime containers shipping companies' Business Process Model (BPMo) and the digital applications used for digitalizing the BPMo.

The lack of published process models for the companies that are the object of this research has required the development of a BPMo. The developed BPMo departed from the Cross-Industry version of the Process Classification Framework@ $[14,15]$ from the 
American Productivity \& Quality Centre (APQC) since there is no version for maritime shipping companies. Figure 1 has the "look and feel" from the APQC, which was used as a starting process model.

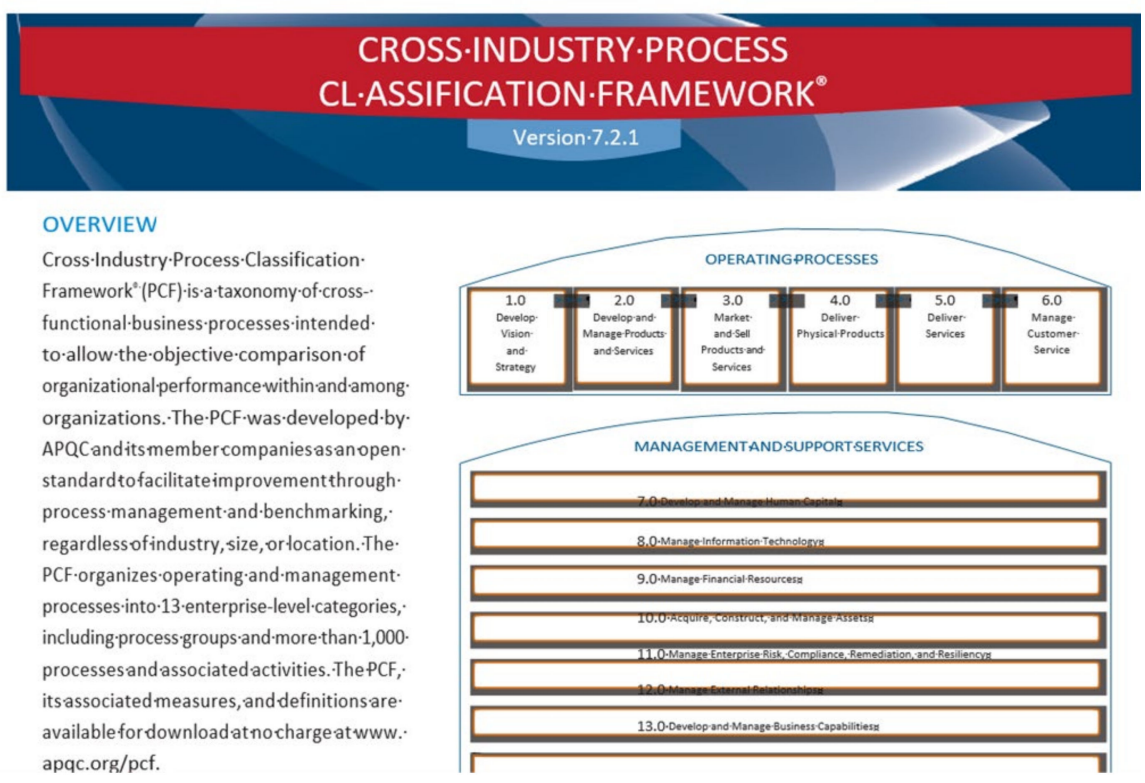

\subsection{Market and Sell Products and Services (10004)}

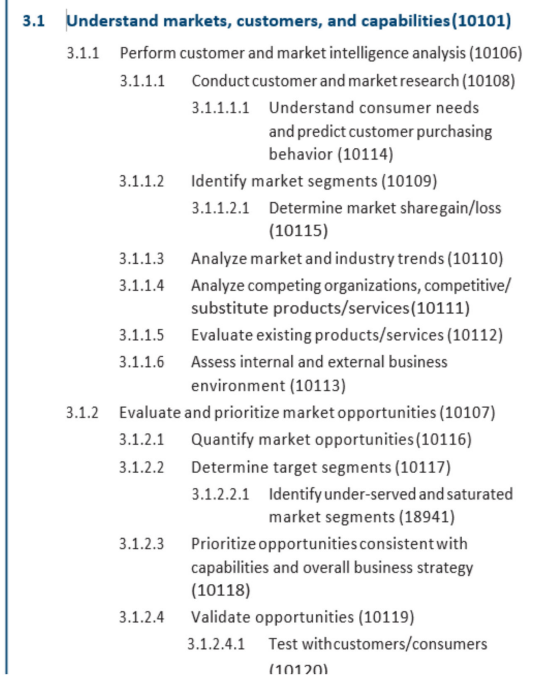

\begin{tabular}{|c|c|c|c|}
\hline & & \multicolumn{2}{|c|}{ partners (10126) } \\
\hline & \multirow[t]{4}{*}{ 3.2.3.7 } & \multicolumn{2}{|c|}{$\begin{array}{l}\text { Orchestrate seamless customer experience } \\
\text { across supported channels (20004) }\end{array}$} \\
\hline & & 3.2.3.7.1 & $\begin{array}{l}\text { Define omni-channelstrategy } \\
\text { (16590) }\end{array}$ \\
\hline & & 3.2.3.7.2 & $\begin{array}{l}\text { Define omni-channel requirements } \\
\text { (16591) }\end{array}$ \\
\hline & & 3.2.3.7.3 & $\begin{array}{l}\text { Develop omni-channel policies and } \\
\text { procedures (16592) }\end{array}$ \\
\hline & 3.2.3.8 & \multicolumn{2}{|c|}{$\begin{array}{l}\text { Develop and manage execution roadmap } \\
\text { (20005) }\end{array}$} \\
\hline \multirow[t]{6}{*}{3.2 .4} & \multicolumn{3}{|c|}{ Analyze and manage channel performance (20006) } \\
\hline & 3.2.4.1 & \multicolumn{2}{|c|}{$\begin{array}{l}\text { Establish channel-specific metrics and targets } \\
\text { (16573) }\end{array}$} \\
\hline & 3.2.4.2 & \multicolumn{2}{|c|}{ Monitor and report performance (16574) } \\
\hline & 3.2.4.3 & \multicolumn{2}{|c|}{$\begin{array}{l}\text { Monitor and report events influencing factors } \\
(16575)\end{array}$} \\
\hline & 3.2.4.4 & \multicolumn{2}{|c|}{ Analyze performance $(16500)$} \\
\hline & 3.2.4.5 & \multicolumn{2}{|c|}{ Develop plan for improvements (16501) } \\
\hline \multirow[t]{5}{*}{ 3.2.5 } & Develop & marketing & communication strategy (16848) \\
\hline & 3.2.5.1 & \multicolumn{2}{|c|}{$\begin{array}{l}\text { Develop customer communication calendar } \\
\text { (16849) }\end{array}$} \\
\hline & 3.2.5.2 & \multicolumn{2}{|c|}{ Define public relations (PR) strategy (16850) } \\
\hline & 3.2.5.3 & \multicolumn{2}{|c|}{ Define direct marketing strategy (16851) } \\
\hline & 3.2.5.4 & \multicolumn{2}{|c|}{$\begin{array}{l}\text { Define internal marketing communication } \\
\text { strategy (16852) }\end{array}$} \\
\hline
\end{tabular}

Figure 1. APQC cross-industry process classification framework.

A first version of the business processes for maritime container shipping companies has been generated by tailoring these cross-industry business processes, taking advantage of the following assets:

- $\quad$ The most relevant handbooks on maritime economics [16,17];

- Published research that includes parts of the business processes for a maritime container shipping company $[9,18]$;

- $\quad$ The UN Convention on International Multimodal Transport [19].

The content validation of this model was performed by using an inter-judge validation process. The experts that participated in this validation were: 
- Three Spanish Maritime Transportation Shipping Companies, including the participation of C-level executives and vice-presidents from these companies.

- A Spanish logistics management company.

- An expert in the sector from Universidad Politécnica de Madrid (UPM).

The content validation of this business process model was performed by using an interjudge validation process. This method has been extensively used specially for validating survey questions. This work makes use of it, extending the concept of content validation beyond the one related with questions from a survey. The quantification of the agreement was calculated using the content validity ratio (CVR) developed by Lawshe [20]:

$$
C V R=(n e-N / 2)(N / 2)
$$

where $n e=$ number of judges indicating the question as "essential" (in this research, $n e=$ number of judges indicating the modification of the BPMo as "essential"); and $N=$ total number of judges (in this work, $N=5$ ).

Lawshe considered the values of CVR included in Table 1 as the ones necessary for item validation.

Table 1. Minimum values of CVR.

\begin{tabular}{cc}
\hline Number of Judges & CVR Min. Value \\
\hline $5-7$ & 0.99 \\
8 & 0.85 \\
9 & 0.78 \\
10 & 0.62 \\
11 & 0.59 \\
12 & 0.56 \\
13 & 0.54 \\
14 & 0.51 \\
15 & 0.49 \\
20 & 0.42 \\
25 & 0.337 \\
30 & 0.33 \\
35 & 0.31 \\
40 & 0.29 \\
\hline
\end{tabular}

Therefore, the method required the agreement amongst judges on the validity and clarity of the model.

The next step was building the list of digital application; three sources have been used for building such a list:

- Applications coming from academic research. These are the ones coming from the aforementioned Sensors paper from the team of this research.

- Applications that are already available in the market. This list has been built using the newsletter from the market. Some of them are: www.maritime-executive.com, www.vpoglobal.com, www.thedigitalship.com, www.dnv.com, www.shippingandfrieghtresource.com, and www.wartsila.com. It includes not only market-available applications but also others that are inspired by market-available ones. The range of dates for this analysis has been between March 2018 and September 2021.

- Applications coming from other industries. The search for these applications was completed via the internet between June 2021 and September 2021.

The list of applications was confronted to the aforementioned BPMo for maritime container shipping companies in order to qualify the impact on each process, the requirements for the implementation of the app, and the Key Performance Indicators (KPIs) that will measure the impact of the implementation.

The digitalization of the processes implies their redesign. The tool for quantifying the impact of this redesign is the devil's quadrangle [21]. This framework evaluates the impact 
using the four performance dimensions for processes: costs, time, quality, and flexibility. In this research, the impact has been quantified using the following criteria:

- Costs: this performance dimension is broken down into two sub-dimensions:

- Implementation costs, which accounts the costs for deploying the application in the company. It has these values:

- $\quad$ Low (equal to 2) for applications that require a low investment for their deployment.

- $\quad$ Medium (equal to 1) for applications that require a medium investment for their deployment.

- $\quad$ High (equal to 0) for applications that require a high investment for their deployment.

The aforementioned values are comparatively weighted (i.e., the values low, medium, and high are relative to the rest of the applications). The comparative analysis situated the applications in one of the three aforementioned tertiles (i.e., low, medium, and high).

- Execution cost, which evaluates the return of investment (ROI). It has these values:

- $\quad$ Low (equal to 2) for applications with an ROI in less than 2 months.

- $\quad$ Medium (equal to 1) for applications with an ROI in 2-12 months.

- $\quad$ High (equal to 0) for applications that need more than 12 months for their ROI.

The final value of the performance indicator is obtained by arithmetic media of the two sub-dimensions.

- Time is also broken down into two sub-dimensions:

- Implementation time, which accounts the time needed for deploying the application in the company. It has these values:

- Low (equal to 2) for applications that can be deployed in less than 6 months.

- $\quad$ (equal to 1) for applications that can be deployed in 6-18 months.

- $\quad$ (equal to 0 ) for applications that need more than 18 months for their deployment.

- Execution time, which evaluates the savings in time for the processes' execution. It has these values:

- $\quad$ High (equal to 2) for applications with a high decrease on processes' execution time.

- $\quad$ Medium (equal to 1) for applications with a medium decrease on processes' execution time.

- $\quad$ Low (equal to 0) for applications with a small decrease on processes' execution time.

The aforementioned values are comparatively weighted (i.e., the values' categorization as low, medium, or high is relative to the rest of the applications). The final value of the performance indicator is obtained by arithmetic media of the two sub-dimensions.

- Quality, that evaluates the reliability added to the processes by the application. It has the following values:

High (equal to 2) for applications with a high increase on the processes' reliability.

- Medium (equal to 1) for applications with a medium increase on the processes' reliability.

- Low (equal to 0) for applications with a small increase on the processes' reliability.

The aforementioned values are comparatively weighted (i.e., the values' categorization as low, medium, or high is relative to the rest of the applications). 
- Flexibility, the performance indicator that evaluates the flexibility that the application has on the company's processes. It has the following values:

- High (equal to 2) for applications with a high increase on the processes' flexibility.

- Medium (equal to 1) for applications with a medium increase on the processes' flexibility.

- Low (equal to 0 ) for applications a small increase on the processes' flexibility. The aforementioned values are comparatively weighted (i.e., the values' categorization as low, medium, is high is relative to the rest of the applications).

The "ideal" application is the one that maximizes the four performance indicators, and therefore, the impact on the company is considered positive. That application will achieve a total score of 8 (i.e., a score of 2 in each of the four performance dimensions for processes).

A data sheet was developed for each of these applications, which has the information from Figure 2.
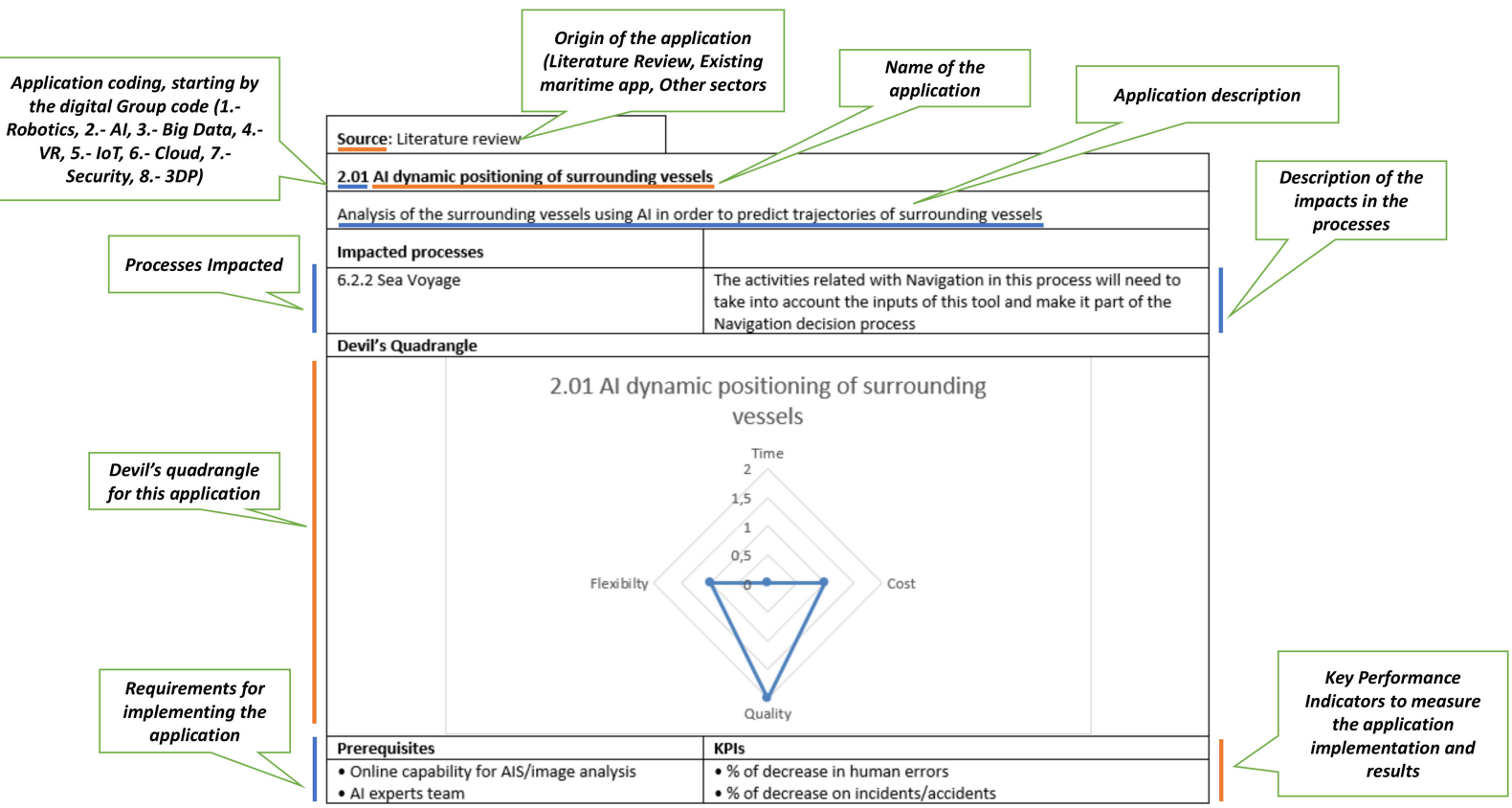

Figure 2. Application data sheet sample.

The impacts on the processes have been analyzed assuming that the application considered is the only one that has been deployed, i.e., that it has been deployed stand alone. The combined deployment of several applications will require a review on the impacts. This same consideration applies to the KPIs: in case of deployment of several applications, the KPIs should be reviewed and confirmed.

\section{Results and Discussion}

The validated BPMo for maritime container shipping companies can be found as additional material of this paper. The application of the methodology from Section 3 resulted in a total of 46 application data sheets that contain the results of the research. These results are the applications data sheets, they have the impacts in the BPMo, and they can be found in Appendix A of the present work.

Regarding the impacts on the processes, a total of 147 impacts have been found. The processes highly impacted by different applications are shown in Table 2. 
Table 2. Processes with more than two impacts.

\begin{tabular}{lc}
\hline \multicolumn{1}{c}{ Process } & Number of Impacts \\
\hline 6.2.2 Sea Voyage & 15 \\
7.3.1 Plan and Execute Ship Daily Maintenance & 9 \\
and Periodical Crew Exercises & 7 \\
6.1.5 Charge Ship & 7 \\
6.3.4 Unload Ship & 6 \\
6.2.1 Unberth Ship & 6 \\
6.2.6 Berth Ship & 5 \\
7.3.1 BIS Analysis of Operational Data & 4 \\
for Maintenance & 4 \\
2.2.1 Analyze Competitors' Routes & 4 \\
6.1.3 Prepare Stowage Plan & 4 \\
6.3.2 Prepare Ship Unloading Plan & \\
9.8.5 Define Safety Framework (Goals, KPIs, & 3 \\
Training, Drills, etc.) & \\
6.1.2 Manage Departure Customs and Rest of & 3 \\
Departure Paperwork & 3 \\
6.3.1 Manage Arrival Customs and Rest of & 3 \\
Arrival Paperwork & 3 \\
9.3.3 Manage Employees Training & \\
9.4.3 Manage Training on Board &
\end{tabular}

The processes with higher impacts are within the operations process categories domain. The reason is that these processes are the ones that produce the wealth of the company, so these are the ones subject to higher investments.

There are six new processes that need to be added to the business process model for different applications:

- $\quad$ 3.3.1 BIS analysis of containers' capabilities. This process is added to the process group "3.3 Acquire/Rent Containers" for application "5.01 Container tracking". The introduction of this application recommends a process to group the tasks and activities related with the different use of a container and the technological capabilities from it in an IoT environment.

- 4.2.2 BIS analysis of liner terms based on AI analysis of client information. This process is added to process group " 4.2 Analyze and Define Liner Terms" for application "2.05 Client offering optimization via AI analysis of client information".

- 6.2.1 BIS start equipment monitorization. This process is added to process group "6.2 Depart, Sea Voyage and Berth" for application "5.02 Optimization of equipment usage".

- 6.2.6 BIS end equipment monitorization. This process is also added to process group "6.2 Depart, Sea Voyage and Berth" for the same reason, the application "5.02 Optimization of equipment usage".

- $\quad$ 7.3.1 BIS analysis of operational data for maintenance. This process is also added to process group "7.3 Ship Maintenance" for applications "2.06 Analysis of engine parameters to anticipate issues", "2.11 Optimizing maintenance process using digital twin and $\mathrm{AI}^{\prime}$, "2.22 Using AI to reduce emissions", "3.02 Big data analysis for energy efficiency", and "3.03 Analysis of data on consumption and emissions for bunkering selection".

- $\quad$ 7.3.1 BIS capture and analysis of ship structure image. This process is added to process group "7.3 Ship Maintenance" for application "2.13 Analysis of ship structure images to anticipate issues".

On the opposite side, there are three processes that will need to be decommissioned due to the introduction of different applications:

- 6.2.4 Technical support at shore; the introduction of applications "1.01 UV-controlling system" or "1.02 Autonomous vessels" makes it unnecessary. 
- 11.5.2 Define development plan; the introduction of application "6.02 Use of SaaS via cloud" makes it unnecessary.

- 11.5.3 Develop and test solution for the same reason mentioned when talking of decommissioning process 11.5.2.

The total number of KPIs used is 51. These KPIs measure the performance of the introduction of the 46 digital applications; this means that on average, there is more than one KPI needed for measuring the performance of the introduction of one application, which is reasonable. Actually, there are only two applications that require only one KPI for tracking their performance: "6.01 Cloud/edge platform" and "7.01 Enhanced cybersecurity" can be measured using KPIs "Percentage of reduction of operational cost" and "Percentage of improvement on cyberattacks prevented", respectively. These two applications tracked only with one KPI are the only ones that are service platforms for the entire company.

It has just been said that the majority of the applications are measured using more than one KPI; actually, the 46 applications required a total of $105 \mathrm{KPIs}$ to measure their performance. Since the number of unique KPIs is 51 , not 105 , this means that many of them are used in more than one application. A total of $11 \mathrm{KPIs}$ are used more than twice; they are used 53 times out of the mentioned 105 (Table 3), so 11 KPIs can measure more than $50 \%$ of what needs to be measured to quantify applications' performance, which is a good number since with this relatively small number of KPIs, a company can track most of their improvements coming from all the digital applications.

Table 3. KPIs used more than twice for measuring application performance.

\begin{tabular}{|c|c|}
\hline KPI & $\begin{array}{c}\text { Number of Applications that Use This KPI to } \\
\text { Measure Their Performance }\end{array}$ \\
\hline $\begin{array}{l}\% \text { improvement on ratio cost using old } \\
\text { process / cost using new process }\end{array}$ & 8 \\
\hline$\%$ of decrease in human errors & 8 \\
\hline $\begin{array}{l}\text { Number of days of improvement in the } \\
\text { decision process }\end{array}$ & 8 \\
\hline$\%$ decrease on annual maintenance hours & 5 \\
\hline$\%$ of decrease on safety incidents & 5 \\
\hline$\%$ of reduction on costs of fuel consumption & 4 \\
\hline$\%$ decrease on mechanical failures & 3 \\
\hline$\%$ of decrease on incidents/accidents & 3 \\
\hline$\%$ of improvement on customer satisfaction & 3 \\
\hline $\begin{array}{l}\% \text { of improvement on end-of-year } \\
\text { financial results }\end{array}$ & 3 \\
\hline$\%$ of reduction on training costs & 3 \\
\hline TOTAL & 53 \\
\hline
\end{tabular}

Section 2 explained how the impact of the introduction of any of these applications in the BPMo has been quantified using the four performance dimensions for processes: Costs, Time, Quality, and Flexibility. Applications have been grouped into three tertiles in order to analyze the results of this quantified impact. The three tertiles are not always equal in size, since being strict on the balance between the three tertiles would have forced the separation in different tertiles of applications that have the same value on a performance dimension. This happens since there are performance dimensions such as costs or time that are made of two sub-dimensions (see Section 2); and the consolidated impact score is calculated from the four performance dimensions.

Table 4 contains the applications that are in the top tertile applying that evaluation. 
Table 4. List of applications with higher consolidated impact score.

\begin{tabular}{lc}
\hline \multicolumn{1}{c}{ Application } & Impact Score \\
\hline 5.01 Container tracking & 8 \\
2.06 Analysis of engine parameters to anticipate issues & 7 \\
7.02 Cargo documents management & 7 \\
2.04 Route optimization via AI analysis of client information & 6.5 \\
4.03 VR for maintenance & 6 \\
2.07 Route optimization via AI analysis of operational information & 6 \\
2.14 Optimizing ship's operations via AI analysis of operational information & 5.5 \\
2.11 Optimizing maintenance process using digital twin and AI & 5.5 \\
2.22 Using AI to reduce emissions & 5.5 \\
3.02 Big data analysis for energy efficiency & 5.5 \\
6.03 Unalysis of data on consumption and emissions for bunkering selection & 5.5 \\
8.01 Spare parts using 3DP & 5.5 \\
1.03 Digital twin for AV controlling and maintenance & 5 \\
1.04 Use of robots in complex/hazardous tasks & 5 \\
2.13 Analysis of ship structure images to anticipate issues & 5 \\
2.21 Using AI to enhance navigation safety & 5 \\
3.06 Big data for ship speed controlling & 5 \\
6.02 Use of SaaS via cloud & 5 \\
\hline
\end{tabular}

Not surprisingly, application "5.01 Container tracking" is leading the score given the following:

- Regarding costs, it is not too expensive to implement, and the return of investment is high, since it enhances containers' delivery process.

- Looking at time, it is also optimal in terms of implementation time (there are many market applications for a quick implementation), and it saves considerable time for tracking the containers.

- The quality of the process increases as the applications are error-prone compared with the manual process.

- The flexibility of the affected processes increases considerably compared to the manual tracking.

On the other side of the list in Table 5, the applications that are in the bottom tertile can be found.

Table 5. List of applications with lower consolidated impact score.

\begin{tabular}{lc}
\hline \multicolumn{1}{c}{ Application } & Impact Score \\
\hline 2.01 AI dynamic positioning of surrounding vessels & 3 \\
3.04 ISPS security levels & 3 \\
5.02 Optimization of equipment usage & 3 \\
5.03 Digital twin for training purposes & 3 \\
1.01 UV controlling system & 2.5 \\
1.02 Autonomous vessels & 2 \\
3.05 Big data for ship renewal & 2 \\
7.01 Enhanced cybersecurity & 2 \\
2.15 AI applied to cybersecurity & 1 \\
2.17 AI applied to competitors tracking and monitoring & 1 \\
2.18 AI applied to business partners tracking and monitoring & 1 \\
2.19 AI applied to providers tracking and monitoring & 1 \\
2.16 AI applied to three parties route prediction & 1 \\
6.01 Cloud/Ed to data management and clean & 0.5 \\
\hline
\end{tabular}

The applications from Table 5 do not necessarily fall into applications that should not be implemented or that should be discarded. What these 15 applications from Table 5 have in common is that they are the lowest when compared with the 46 applications; this should not prevent companies from the implementation of any of them, it is just that they need to know these have more costs or require more time for their deployment and for benefits realization. Actually, there are two of them that are service platforms for the rest: "6.01 Cloud/Edge platform" and "7.01 Enhanced cybersecurity".

The analysis can be taken to a level below the ones conducted so far by looking at the results obtained in each performance dimension. When looking at the list of top applications on time performance dimension (Table 6), there is one application that is top when looking at time performance but is not only not included in the top list for consolidated impact but is in the bottom side, so it is included in Table 5: it is "3.04 ISPS security levels". The reason is that this application does not increase substantially the flexibility or the quality of the affected processes compared with the rest of the 46 applications. 
Table 6. Top applications on Time performance dimension.

\begin{tabular}{lc}
\hline \multicolumn{1}{c}{ Application } & Impact Score \\
\hline 4.01 VR for training & 2 \\
4.03 VR for maintenance & 2 \\
5.01 Container tracking & 2 \\
6.02 Use of SaaS via cloud & 2 \\
6.03 Use of eLearning via cloud & 2 \\
7.02 Cargo documents management & 2 \\
7.04 Electronic logbook & 2 \\
1.04 Use of robots in complex/hazardous tasks & 1.5 \\
2.04 Route optimization via AI analysis of client information & 1.5 \\
2.06 Analysis of engine parameters to anticipate issues & 1.5 \\
2.07 Route optimization via AI analysis of operational information & 1.5 \\
2.10 Fleet dimensioning optimization & 1.5 \\
2.12 Conversational virtual assistance for helping seafarers in day-to-day activities & 1.5 \\
3.02 Big data analysis for energy efficiency & 1.5 \\
3.03 Analysis of data on consumption and emissions for bunkering selection & 1.5 \\
3.04 ISPS security levels & 1.5 \\
3.06 Big data for ship speed controlling & 1.5 \\
8.01 Spare parts using 3DP & 1.5 \\
\hline
\end{tabular}

One application is found in the opposite situation: being in the list of top performers when looking at the consolidated (Table 4); it is at the bottom side when looking at the time performance dimension (Table 7). This is the case of "2.14 Optimizing ship's operations via AI analysis of operational information". This application scores 6/8 in the consolidated impact score given it is outstanding when compared to others in the Flexibility and Quality provided to the affected processes, and its availability in the current market makes it almost optimal when looking at Costs.

Table 7. Bottom applications on Time performance dimension.

\begin{tabular}{lc}
\hline \multicolumn{1}{c}{ Application } & Impact Score \\
\hline 2.02 Assessment of ship risks using fuzzy logic & 0.5 \\
2.08 Process optimization and reengineering using AI & 0.5 \\
2.09 Freight rate optimization & 0.5 \\
2.14 Optimizing ship's operations via AI analysis of operational information & 0.5 \\
5.02 Optimization of equipment usage & 0.5 \\
1.01 UV controlling system & 0 \\
1.02 Autonomous vessels & 0 \\
2.01 AI dynamic positioning of surrounding vessels & 0 \\
2.15 AI applied to cybersecurity & 0 \\
2.16 AI applied to data management and clean & 0 \\
2.17 AI applied to competitors tracking and monitoring & 0 \\
2.19 AI applied to business partners tracking and monitoring & 0 \\
2.20 AI applied to 3 parties tracking and monitoring & 0 \\
6.01 Cloud/Edge platform & 0 \\
\hline
\end{tabular}

Moving to Costs, two applications are at the top for this performance dimension (Table 8) and at the bottom when looking at the consolidated score (Table 5). These are "3.04 ISPS security levels" and "5.02 Optimization of equipment usage". The first one was found in the same situation when looking at Time, and the reason is the same: it does not increase substantially the flexibility or the quality of the affected processes compared with the rest of the 46 applications. Regarding " 5.02 Optimization of equipment usage", it does not increase flexibility or quality, and it is also low when looking at Time, since it is not available on the market yet.

As it happened when analyzing Time, one application is found in the bottom list from Costs (Table 9) and at the top when looking at the consolidated score (Table 4); this is "2.11 Optimizing maintenance process using digital twin and AI" given it is outstanding when compared to others in the Flexibility and Quality provided to the affected processes, but the cost of a digital twin makes it go down in the list when looking only at this performance dimension.

The next performance dimension to be looked into is Quality. In it, there are two applications that are in the top for this performance dimension (Table 10), whereas they are part of the list of bottom applications in the consolidated score (Table 5). These are "1.01 UV controlling system" and "1.02 Autonomous vessels", which have a very high impact on quality improvement for the affected processes but perform very low in the rest of the 
variables (high costs, high time of ROI and implementation, and without a substantial impact in flexibility compared to the others).

Table 8. Top applications on Cost performance dimension.

\begin{tabular}{lc}
\hline \multicolumn{1}{c}{ Application } & Impact Score \\
\hline 2.04 Route optimization via AI analysis of client information & 2 \\
3.02 Big data analysis for energy efficiency & 2 \\
3.03 Analysis of data on consumption and emissions for bunkering selection & 2 \\
5.01 Container tracking & 2 \\
7.02 Cargo documents management & 2 \\
7.04 Electronic logbook & 2 \\
8.01 Spare parts using 3DP & 2 \\
1.04 Use of robots in complex/hazardous tasks & 1.5 \\
2.02 Assessment of ship risks using fuzzy logic & 1.5 \\
2.06 Analysis of engine parameters to anticipate issues & 1.5 \\
2.07 Route optimization via AI analysis of operational information & 1.5 \\
2.13 Analysis of ship structure images to anticipate issues & 1.5 \\
2.14 Optimizing ship's operations via AI analysis of operational information & 1.5 \\
2.22 Using AI to reduce emissions & 1.5 \\
3.01 Big data algorithm for collision avoidance & 1.5 \\
3.04 ISPS security levels & 1.5 \\
3.06 Big data for ship speed controlling & 1.5 \\
4.03 VR for maintenance & 1.5 \\
5.02 Optimization of equipment usage & 1.5 \\
6.03 Use of eLearning via cloud & 1.5
\end{tabular}

Table 9. Bottom applications on Cost performance dimension.

\begin{tabular}{lc}
\hline \multicolumn{1}{c}{ Application } & Impact Score \\
\hline 1.01 UV controlling system & 0.5 \\
2.03 Pricing market prediction & 0.5 \\
2.05 Client offering optimization via AI analysis of client information & 0.5 \\
2.11 Optimizing maintenance process using digital twin and AI & 0.5 \\
2.16 AI applied to data management and clean & 0.5 \\
6.01 Cloud/Edge platform & 0.5 \\
7.03 Blockchain-based Incoterms & 0.5 \\
1.02 Autonomous vessels & 0 \\
1.03 Digital twin for AV controlling and maintenance & 0 \\
2.08 Process optimization and reengineering using AI & 0 \\
2.10 Fleet dimensioning optimization & 0 \\
2.17 AI applied to competitors tracking and monitoring & 0 \\
2.18 AI applied to business partners tracking and monitoring & 0 \\
2.19 AI applied to providers tracking and monitoring & 0 \\
2.20 AI applied to 3 parties route prediction & 0 \\
3.05 Big data for ship renewal & 0 \\
5.03 Digital twin for training purposes & 0 \\
\hline
\end{tabular}

Table 10. Top applications on Quality performance dimension.

\begin{tabular}{lc}
\hline \multicolumn{1}{c}{ Application } & Impact Score \\
\hline 1.01 UV controlling system & 2 \\
1.02 Autonomous vessels & 2 \\
1.03 Digital twin for AV controlling and maintenance & 2 \\
1.04 Use of robots in complex/hazardous tasks & 2 \\
2.06 Analysis of engine parameters to anticipate issues & 2 \\
2.11 Optimizing maintenance process using digital twin and AI & 2 \\
2.14 Optimizing ship's operations via AI analysis of operational information & 2 \\
2.21 Using AI to enhance navigation safety & 2 \\
2.22 Using AI to reduce emissions & 2 \\
3.02 Big data analysis for energy efficiency & 2 \\
3.03 Analysis of data on consumption and emissions for bunkering selection & 2 \\
4.03 VR for maintenance & 2 \\
5.01 Container tracking & 2 \\
7.02 Cargo documents management & 2 \\
7.03 Blockchain-based Incoterms & 2 \\
\hline
\end{tabular}

Comparing Table 11 (bottom applications for Quality performance dimension) and Table 4 (top consolidated score), applications "6.02 Use of SaaS via cloud", "6.03 Use of eLearning via cloud" and "8.01 Spare parts using 3DP" are in both lists due to the same reason: they do not increase substantially the quality of the affected processes when compared to others, whereas they perform well on the rest of the performance dimensions. 
Table 11. Bottom applications on Quality performance dimension.

\begin{tabular}{lc}
\hline \multicolumn{1}{c}{ Application } & Impact Score \\
\hline 2.02 Assessment of ship risks using fuzzy logic & 0 \\
2.15 AI applied to cybersecurity & 0 \\
2.16 AI applied to data management and clean & 0 \\
2.17 AI applied to competitors tracking and monitoring & 0 \\
2.18 AI applied to business partners tracking and monitoring & 0 \\
2.19 AI applied to providers tracking and monitoring & 0 \\
2.20 AI applied to 3 parties route prediction & 0 \\
3.04 ISPS security levels & 0 \\
4.01 VR for training & 0 \\
6.01 Cloud/Edge platform & 0 \\
6.02 Use of SaaS via cloud & 0 \\
6.03 Use of eLearning via cloud & 0 \\
7.01 Enhanced cybersecurity & 0 \\
7.04 Electronic logbook & 0 \\
8.01 Spare parts using 3DP & 0 \\
\hline
\end{tabular}

Moving to the last performance dimension, Flexibility, comparing Table 12 (top performers in Flexibility) and Table 5 (bottom in consolidated score), there is no application in both lists.

Table 12. Top applications on Flexibility performance dimension.

\begin{tabular}{lc}
\hline \multicolumn{1}{c}{ Application } & Impact Score \\
\hline 1.03 Digital twin for AV controlling and maintenance & 2 \\
2.02 Assessment of ship risks using fuzzy logic & 2 \\
2.03 Pricing market prediction & 2 \\
2.04 Route optimization via AI analysis of client information & 2 \\
2.05 Client offering optimization via AI analysis of client information & 2 \\
2.06 Analysis of engine parameters to anticipate issues & 2 \\
2.07 Route optimization via AI analysis of operational information & 2 \\
2.08 Process optimization and reengineering using AI & 2 \\
2.09 Freight rate optimization & 2 \\
2.10 Fleet dimensioning optimization & 2 \\
2.11 Optimizing maintenance process using digital twin and AI & 2 \\
5.01 Contimizing ship's operations via AI analysis of operational information & 2 \\
6.02 Use of SaaS via cloud & 2 \\
6.03 Use of eLearning via cloud & 2 \\
8.01 Spare parts using 3DP & 2 \\
\hline
\end{tabular}

However, doing the same exercise with bottom applications in Flexibility (Table 13) and top performers in consolidated score (Table 4), there are three applications in both lists: "1.04 Use of robots in complex/hazardous tasks", "3.02 Big data analysis for energy efficiency", and "3.03 Analysis of data on consumption and emissions for bunkering selection", all of them outperforming in the rest of the performance dimensions.

Table 13. Bottom applications on Flexibility performance dimension.

\begin{tabular}{lc}
\hline \multicolumn{1}{c}{ Application } & Impact Score \\
\hline 1.01 UV controlling system & 0 \\
1.02 Autonomous vessels & 0 \\
1.04 Use of robots in complex/hazardous tasks & 0 \\
2.12 Conversational virtual assistance for helping seafarers in day-to-day activities & 0 \\
2.15 AI applied to cybersecurity & 0 \\
2.16 AI applied to data management and clean & 0 \\
3.01 Big data algorithm for collision avoidance & 0 \\
3.02 Big data analysis for energy efficiency & 0 \\
3.03 Analysis of data on consumption and emissions for bunkering selection & 0 \\
3.04 ISPS security levels & 0 \\
3.05 Big data for ship Renewal & 0 \\
5.02 Optimization of equipment usage & 0 \\
6.01 Cloud/Edge platform & 0 \\
7.01 Enhanced cybersecurity & 0 \\
7.04 Electronic logbook & 0 \\
\hline
\end{tabular}

To finalize the analysis of results, we identified the 10 applications that can be named as "quick wins". These are applications that, given their optimal results on the Time performance dimension and good results on the Costs performance dimension, could be considered as the starting point for digitalizing a company. A company starting its 
digitalization with these could obtain a sense of what digitalization is and learn lessons of the implementation project, which will be value for going to the next step.

The list has been obtained by sorting the results of the score of the devil's quadrant first by those performing better on Time, then on Costs, and finally on consolidated global score. The list is in Table 14.

Table 14. Quick-win applications.

\begin{tabular}{lccc}
\hline \multicolumn{1}{c}{ Application } & Time & Costs & Global Impact \\
\hline 5.01 Container tracking & 2 & 2 & 8 \\
7.02 Cargo documents management & 2 & 2 & 7 \\
7.04 Electronic logbook & 2 & 2 & 4 \\
4.03 VR for maintenance & 2 & 1.5 & 6.5 \\
6.03 Use of eLearning via cloud & 2 & 1.5 & 5.5 \\
6.02 Use of SaaS via cloud & 2 & 1 & 5 \\
4.01 VR for training & 2 & 1 & 6 \\
2.04 Route optimization via AI analysis of client information & 1.5 & 2 & 6.5 \\
3.02 Big data analysis for energy efficiency & 1.5 & 2 & 5.5 \\
3.03 Analysis of data on consumption and emissions for & 1.5 & 2 & 5.5 \\
bunkering selection & & & \\
\hline
\end{tabular}

The majority of these are in Table 4 (List of applications with higher consolidated impact score); they are applications that are top performers in the consolidated impact score. The exceptions are "7.04 Electronic logbook" and "4.01 VR for training". These two do not score as high as others when looking at the consolidated score but can be good candidates for testing the benefits of digitalization in one company, given their ease of implementation.

Summing up the analysis of the results, the main outcomes are as follows:

- The processes with higher impacts are within the Operations process categories domain. The reason is that these processes are the ones that produce the wealth of the company, so these are the ones subject to higher investments. The one more frequently impacted is "6.2.2 Sea Voyage"; this will be impacted by $32.6 \%$ of the applications.

- There are six new processes that will be necessary when implementing some applications from AI or IoT domains. These processes are from the Strategy, Infrastructure \& Products and from the Operations process categories domains.

- $\quad$ On the other side, there are three processes that will need to be decommissioned when implementing two applications (one from the Cloud digital domain and one from the Robotics one). They are within the Operations and the Enterprise Management process categories domains.

- The KPIs needed for measuring the performance of the digitalization of the BPMo are 51 , though 11 of them can measure more than $50 \%$ of what is necessary for tracking the outcomes of the digitalization.

- The quantification of the impacts performed with the devil's quadrant gives a perspective on how the digitalization can benefit a company for implementing an application, but it does not necessary imply that applications in the bottom of the list should not be implemented; the decision of going for one application or another should be made by the company looking at its priorities and needs. There are some conclusions though coming from the results of this analysis:

Applications "5.01 Container tracking”, "2.06 Analysis of engine parameters to anticipate issues", and "7.02 Cargo documents management" are at the top of the list of the consolidated impact score. These applications are market available which, together with the nature of the application, makes the Time and Costs performance dimensions better when compared to others. They are also in the top of the list in Quality.

- Applications "2.16 AI applied to data management and clean" and "6.01 Cloud/Edge platform" are at the bottom of the list, though especially the last one is necessary for others to work (i.e., it is a prerequisite for implementing a number of other applications). 
There are applications that are at the top when looking at the consolidated score but at the bottom when looking at one performance dimension. This is the case for "2.14 Optimizing ship's operations via AI analysis of operational information" (bottom in Time but top in Flexibility and Quality and almost optimal in Costs), and it is also the case for "2.11 Optimizing maintenance process using digital twin and AI" (bottom in Costs but top in Flexibility and Quality and average in Time). This happens also with "6.02 Use of SaaS via cloud", "6.03 Use of eLearning via cloud", and "8.01 Spare parts using 3DP" (low in Quality but much better in the rest of performance dimensions), and with "1.04 Use of robots in complex/hazardous tasks", "3.02 Big data analysis for energy efficiency", and "3.03 Analysis of data on consumption and emissions for bunkering selection" (same situation just described but with Flexibility rather than Quality.

The opposite also happens: applications that are at the bottom when looking at consolidated score are at the top for one performance dimension. This is the case of "3.04 ISPS security levels" (top in Time and Costs but bottom in Flexibility and Quality), "5.02 Optimization of equipment usage" (top in Costs but bottom or almost at the bottom in the rest). This happens also with "1.01 UV controlling system" and "1.02 Autonomous vessels" (top in Quality and low in the rest).

- A list of 10 applications has been identified as "quick wins" applications that can be the starting point for digitalizing a company given their optimal results on the Time performance dimension and good results on the Costs performance dimension.

\section{Conclusions}

This work analyzes the impact of digitalization in a part of the maritime transport industry, the maritime containers shipping companies. This research has been conducted in order to help the digitalization of this industry, in particular in the aforementioned companies: digitalization in today's world is required for remaining competitive.

The analysis of the introduction of digital applications in the Business Process Model of maritime containers shipping companies shows that digitalization is feasible for these companies and can be completed at different paces. Each company should make a specific and detailed plan for digitalization, according to their needs and environment. They can leverage the work presented here on the applications and the KPIs that should measure the implementation of any of these applications.

Companies can also benefit from the identification of the applications named in this work as "quick wins"; these applications can be a sandbox that can be used to test the benefits of digitalization and learn how to best execute the deployment customized to the needs of the company. Application "5.01 Container tracking" is in the top of the list of these "quick wins" given its optimal behavior when looking at the four performance dimensions for processes (Time, Costs, Quality, and Flexibility).

The impact of digitalization is high when trying to deploy all the applications at the same time in a big bang approach. Such an approach is not advisable not only given the high investment it requires but also due to the risks that such a huge effort poses for a company. Companies should consider the impacts in their processes and the applications prerequisites documented for each application in Section 3 of this work. They should also review their existing balanced scorecard incorporating the application's KPIs documented in the aforementioned section. The KPIs defined are 51, but with 11 of them, a company can track the majority of the impacts of an application deployment.

A relevant outcome of the analysis of the results of the impacts in processes is that the Operational process categories domain is the one with higher impacts. This is a consequence of the applications trying to impact the processes that generate the company's incomes. Looking at the rest of the process categories domains, there is one process that stands out 
from the rest, "Analyze Competitors Routes". This process from the Strategy, Infrastructure, and Products process categories domain is impacted by four different applications given the importance that the market and the research is given to a company's strategy.

Digitalizing a company imposes changes in their processes and the definition of new processes as well as the decommissioning of others. In other words, digitalization will change the way a company operates. This is something that must be taken into account when defining the deployment plan of the applications, educating their personnel in the new way of doing things and the benefits that this will bring.

Digitalization has many impacts in the company's operations but a plan well defined, in which the impacts and prerequisites are detailed and where a number of KPIs is included to track the deployment's performance, is the key for success. This work covers these aspects in order to allow a successful digitalization.

Author Contributions: P.-L.S.-G. designed the methodology and applied it to obtain the results; D.D.-G. and L.R.N.-R. analyzed the results and provided feedback on the reporting; P.-L.S.-G. wrote the work. All authors have read and agreed to the published version of the manuscript.

Funding: This research is under consideration for funding by Fundación Marqués de Suanzes and by Soermar Chair from Universidad Politécnica de Madrid.

Institutional Review Board Statement: Not applicable.

Informed Consent Statement: Not applicable.

Conflicts of Interest: The authors declare no conflict of interest.

\section{Appendix A Application Data Sheets}

\begin{tabular}{|l|}
\hline Source: Literature review \\
\hline 1.01 UV controlling system \\
\hline System for controlling the unmanned vessel. There are different types: straight line patch, non-linear line-of-sight, approach controller, etc. \\
\hline Impacted processes \\
\hline
\end{tabular}

Figure A1. Cont. 


\begin{tabular}{|c|c|}
\hline 2.3.4 Analyze Ports Windows and Infrastructure & $\begin{array}{l}\text { The analysis should include the port facilities for unmanned vessels as well as the local } \\
\text { regulations on them. }\end{array}$ \\
\hline 6.1.1 Receive and Process Charge Documentation & The documentation will be received by the ground crew. \\
\hline $\begin{array}{l}\text { 6.1.2 Manage Departure Customs and Rest of Depar- } \\
\text { ture Paperwork }\end{array}$ & These activities will rely on ground staff. \\
\hline 6.1.3 Prepare Stowage Plan & The stowage plan will be prepared by the ground crew. \\
\hline 6.1.4 Complete Departure Preparation & $\begin{array}{l}\text { Departure will be split into two types of staff: administrative staff that will take care of paper- } \\
\text { work and seafarers that will take care of reviewing the readiness of the vessel for the naviga- } \\
\text { tion. }\end{array}$ \\
\hline 6.1.5 Charge Ship & $\begin{array}{l}\text { These activities will be very similar to the current ones. There will be some adaptations to the } \\
\text { fact that the ship is unmanned; for example, the captain and the bridge crew will be on land } \\
\text { controlling the process instead of in the bridge }\end{array}$ \\
\hline 6.2.1 Unberth Ship & The process will change in all its content given that the control will be off the ship. \\
\hline 6.2.2 Sea Voyage & The process will change in all its content given that the control will be off the ship. \\
\hline 6.2.3 Logistics Coordination at Shore & Its content will remain the same but the players will no longer be on board. \\
\hline 6.2.4 Technical Support at Shore & Process will be decommissioned. \\
\hline 6.2.5 Prepare for Port of Arrival Activities & The interactions will be split among vessel, crew on land, and third parties. \\
\hline 6.2.6 Berth ship & The process will change in all its content given that the control will be off the ship. \\
\hline $\begin{array}{l}\text { 6.3.1 Manage Arrival Customs and Rest of Arrival } \\
\text { Paperwork }\end{array}$ & Minor changes coming from the fact that crew will be off board. \\
\hline 6.3.2 Prepare Ship Unloading Plan & $\begin{array}{l}\text { These activities will be very similar to the current ones. There will be some adaptations to the } \\
\text { fact that the ship is unmanned; for example, the captain and the bridge crew will be on land } \\
\text { controlling the process instead of in the bridge. }\end{array}$ \\
\hline 6.3.3 Prepare for Shore Logistics & These activities will rely on ground staff. \\
\hline 6.3.4 Unload Ship & $\begin{array}{l}\text { These activities will be very similar to the current ones. There will be some adaptations to the } \\
\text { fact that the ship is unmanned; for example, the captain and the bridge crew will be on land } \\
\text { controlling the process instead of in the bridge. }\end{array}$ \\
\hline $\begin{array}{l}\text { 7.3.1 Plan and Execute Ship Daily Maintenance and } \\
\text { Periodical Crew Exercises }\end{array}$ & $\begin{array}{l}\text { The maintenance will need to be completed remotely and will rely on sensors information as } \\
\text { well as on automatic tools. There is a need of having resources for boarding the ship for some } \\
\text { high-priority maintenance activities. }\end{array}$ \\
\hline 9.3.1 Manage Staffing Needs & $\begin{array}{l}\text { There needs to be a new profile of ground employees that will have a crew profile given the } \\
\text { high number of crew activities. }\end{array}$ \\
\hline 9.4.1 Manage Boarding Process & $\begin{array}{l}\text { The crew will no longer board, but the activities will need to be completed with this sole ex- } \\
\text { ception. }\end{array}$ \\
\hline 9.4.4 Manage Disembark Process & $\begin{array}{l}\text { The crew will no longer board, but the activities will need to be completed with this sole ex- } \\
\text { ception. }\end{array}$ \\
\hline \multicolumn{2}{|l|}{ Devil's quadrangle } \\
\hline & $1.01 \mathrm{UV}$ controlling system \\
\hline Prerequisites & KPIs \\
\hline $\begin{array}{l}\text { - IoT integration } \\
\text { - Autonomous controls in the ships } \\
\text { - Could/Edge network in the ships }\end{array}$ & $\begin{array}{l}\text { - Percentage of decrease in human errors } \\
\text { - Crew cost decrease } \\
\text { - Percentage of improvement in ratio space for cargo space for crew } \\
\text { - Percentage of increase in ship utilization }\end{array}$ \\
\hline
\end{tabular}

Figure A1. UV controlling system data sheet. 


\begin{tabular}{|c|c|}
\hline Source: Existing maritime app & \\
\hline 1.02 Autonomous vessels & \\
\hline Navigation directly controlled from earth, reducing c & and human errors \\
\hline Impacted processes & \\
\hline 6.1.1 Receive and Process Charge Documentation & The documentation will be received by the ground crew. \\
\hline $\begin{array}{l}\text { 6.1.2 Manage Departure Customs and Rest of De- } \\
\text { parture Paperwork }\end{array}$ & These activities will rely on ground staff. \\
\hline 6.1.3 Prepare Stowage Plan & The stowage plan will be prepared by the ground crew. \\
\hline 6.1.4 Complete Departure Preparation & $\begin{array}{l}\text { Departure will be split in two types of staff: administrative staff that will take care of paper- } \\
\text { work, and seafarers that will take care of reviewing the readiness of the vessel for the naviga- } \\
\text { tion }\end{array}$ \\
\hline 6.1.5 Charge Ship & $\begin{array}{l}\text { These activities will be completed very similar to the current one. There will be some adapta- } \\
\text { tions to the fact that the ship is unmanned; for example, the captain and the bridge crew will } \\
\text { be on land controlling the process instead of in the bridge. }\end{array}$ \\
\hline 6.2.1 Unberth Ship & The process will change in all its content given that the control will be off the ship. \\
\hline 6.2.2 Sea Voyage & The process will change in all its content given that the control will be off the ship. \\
\hline 6.2.3 Logistics Coordination at Shore & Its content will remain the same but the players will no longer be on board. \\
\hline 6.2.4 Technical Support at Shore & The process will be decommissioned. \\
\hline 6.2.5 Prepare for Port of Arrival Activities & The interactions will be split among the vessel, crew on land, and third parties. \\
\hline 6.2.6 Berth Ship & The process will change in all its content given that the control will be off the ship. \\
\hline $\begin{array}{l}\text { 6.3.1 Manage Arrival Customs and Rest of Arrival } \\
\text { Paperwork }\end{array}$ & Minor changes coming from the fact that the crew will be off board. \\
\hline 6.3.2 Prepare Ship Unloading Plan & $\begin{array}{l}\text { These activities will be completed very similar to the current one. There will be some adapta- } \\
\text { tions to the fact that the ship is unmanned; for example, the captain and the bridge crew will } \\
\text { be on land controlling the process instead of in the bridge. }\end{array}$ \\
\hline 6.3.3 Prepare for Shore Logistics & These activities will rely on ground staff. \\
\hline 6.3.4 Unload Ship & $\begin{array}{l}\text { These activities will be completed very similar to the current one. There will be some adapta- } \\
\text { tions to the fact that the ship is unmanned; for example, the captain and the bridge crew will } \\
\text { be on land controlling the process instead of in the bridge }\end{array}$ \\
\hline Devil's quadrangle & \\
\hline & 1.02 Autonomous vessels \\
\hline Prerequisites & KPIs \\
\hline $\begin{array}{l}\text { - IoT integration } \\
\text { - Autonomous controls in the ships } \\
\text { - Could/Edge network in the ships }\end{array}$ & $\begin{array}{l}\text { - Percentage of decrease in human errors } \\
\text { - Crew cost decrease } \\
\text { - Percentage of improvement in ratio space for cargo space for crew } \\
\text { - Percentage of increase in ship utilization }\end{array}$ \\
\hline
\end{tabular}

Figure A2. Autonomous vessels data sheet.

\begin{tabular}{|l|l|}
\hline \multicolumn{2}{|l|}{ Source: Existing maritime app } \\
\cline { 1 - 2 } 1.03 Digital twin for AV controlling and maintenance \\
\hline Leverage in the digital twin to better control UV and to help in maintenance \\
\hline Impacted processes & $\begin{array}{l}\text { The process needs to integrate the digital twin in its activities (e.g., simulations of stow- } \\
\text { age in the digital twin). }\end{array}$ \\
\hline 6.1.3 Prepare Stowage Plan & $\begin{array}{l}\text { The process needs to integrate the digital twin in its activities, mainly on } \\
\text { troubleshooting actions. }\end{array}$ \\
\hline 6.1.5 Charge Ship &
\end{tabular}

Figure A3. Cont. 


\begin{tabular}{|c|c|}
\hline 6.2.1 Unberth Ship & $\begin{array}{l}\text { The process needs to integrate the digital twin in its activities, mainly on troubleshooting ac- } \\
\text { tions. }\end{array}$ \\
\hline 6.2.2 Sea Voyage & $\begin{array}{l}\text { The process needs to integrate the digital twin in its activities, mainly on troubleshooting ac- } \\
\text { tions. }\end{array}$ \\
\hline 6.2.6 Berth Ship & $\begin{array}{l}\text { The process needs to integrate the digital twin in its activities, mainly on troubleshooting ac- } \\
\text { tions. }\end{array}$ \\
\hline 6.3.2 Prepare Ship Unloading Plan & $\begin{array}{l}\text { The process needs to integrate the digital twin in its activities (e.g., simulations of unloading in } \\
\text { the digital twin). }\end{array}$ \\
\hline 6.3.4 Unload Ship & $\begin{array}{l}\text { The process needs to integrate the digital twin in its activities, mainly on troubleshooting ac- } \\
\text { tions. }\end{array}$ \\
\hline $\begin{array}{l}\text { 7.3.1 Plan and Execute Ship Daily Maintenance and } \\
\text { Periodical Crew Exercises }\end{array}$ & $\begin{array}{l}\text { The maintenance activities will now leverage on the digital twin for the preparation and trou- } \\
\text { bleshooting. }\end{array}$ \\
\hline \multicolumn{2}{|l|}{ Devil's quadrangle } \\
\hline & 1.03 Digital twin for AV controlling and \\
\hline Prerequisites & KPIs \\
\hline $\begin{array}{l}\text { - Digital twin } \\
\text { - IoT integration } \\
\text { - Autonomous controls in the ships } \\
\text { - Could/Edge network in the ships }\end{array}$ & $\begin{array}{l}\text { - Percentage of decrease in human errors } \\
\text { - Percentage of improvement on maintenance costs }\end{array}$ \\
\hline
\end{tabular}

Figure A3. Digital twin for AV controlling and maintenance data sheet.

\begin{tabular}{|c|c|c|}
\hline Source: Existing maritime app & & \\
\hline \multicolumn{3}{|l|}{1.04 Use of robots in complex/hazardous tasks } \\
\hline \multicolumn{3}{|c|}{ Make use of robots to avoid the exposure of the crew to risks (checks of cargo, underwater surveys, antifouling, etc.) } \\
\hline \multicolumn{3}{|c|}{\begin{tabular}{|l|l} 
Impacted processes & \\
\end{tabular}} \\
\hline 6.1.3 Prepare Stowage Plan & \multicolumn{2}{|c|}{ The preparation will need to take into account the readiness of these robots. } \\
\hline 6.1.5 Charge Ship & \multicolumn{2}{|c|}{ The activities will need to change to integrate the robots into them. } \\
\hline 6.3.2 Prepare Ship Unloading Plan & \multicolumn{2}{|c|}{ The preparation will need to take into account the readiness of these robots. } \\
\hline 6.3.4 Unload Ship & \multicolumn{2}{|c|}{ The activities will need to change to integrate the robots into them. } \\
\hline $\begin{array}{l}\text { 7.3.1 Plan and Execute Ship Daily Maintenance and } \\
\text { Periodical Crew Exercises }\end{array}$ & \multicolumn{2}{|c|}{$\begin{array}{l}\text { The plan will need to make sure robots are available for the activities. The execution will need } \\
\text { to change some of the activities that will now be executed by robots. }\end{array}$} \\
\hline \multicolumn{3}{|l|}{ Devil's quadrangle } \\
\hline \multicolumn{3}{|c|}{1.04 Use of robots in complex/hazardous tasks } \\
\hline Prerequisites & \multicolumn{2}{|l|}{ KPIs } \\
\hline $\begin{array}{l}\text { - Robots } \\
\text { - Could/Edge network in the ships }\end{array}$ & \multicolumn{2}{|c|}{$\begin{array}{l}\text { - Percentage of decrease in human errors } \\
\text { - Percentage of increase in efficiency on these tasks }\end{array}$} \\
\hline
\end{tabular}

Figure A4. Use of robots in complex/hazardous tasks data sheet. 


\begin{tabular}{|c|c|c|}
\hline \multicolumn{3}{|l|}{ Source: Literature review } \\
\hline \multicolumn{3}{|c|}{2.01 AI dynamic positioning of surrounding vessels } \\
\hline \multicolumn{3}{|c|}{ Analysis of the surrounding vessels using AI in order to predict the trajectories of the surrounding vessels } \\
\hline \multicolumn{3}{|c|}{\begin{tabular}{l|l} 
Impacted processes & \\
\end{tabular}} \\
\hline 6.2.2 Sea Voyage & $\begin{array}{l}\text { The activities related with navigation } \mathrm{i} \\
\text { of this tool and make it part of the navi }\end{array}$ & $\begin{array}{l}\text { rocess will need to take into account the inputs } \\
\text { decision process. }\end{array}$ \\
\hline \multicolumn{3}{|l|}{ Devil's quadrangle } \\
\hline & $\begin{array}{l}\text { 2.01 Al dynamic positioning of surrounding } \\
\text { vessels }\end{array}$ & \\
\hline Prerequisites & KPIs & \\
\hline $\begin{array}{l}\text { - Online capability for AIS/image analysis } \\
\text { - AI experts team }\end{array}$ & $\begin{array}{l}\text { - Percentage of decrease in human err } \\
\text { - Percentage of decrease on incidents/a }\end{array}$ & \\
\hline
\end{tabular}

Figure A5. AI dynamic positioning of surrounding vessels data sheet.

\begin{tabular}{|c|c|c|}
\hline $\begin{array}{l}\text { Source: Literature review } \\
\text { Other industry app }\end{array}$ & & \\
\hline 2.02 Assessment of ship risks using fuzzy logic & & \\
\hline $\begin{array}{l}\text { Analysis of ships previous to the acquisition for } \\
\text { markets, among others) }\end{array}$ & ning risks associated with it. Applies both & $v$ and existing ships (prediction of future \\
\hline Impacted processes & & \\
\hline $\begin{array}{l}\text { 3.2.1 Analyze Freights Evolution and Ships De- } \\
\text { mand }\end{array}$ & $\begin{array}{l}\text { The activities of this process will be upd } \\
\text { analysis using AI techniques. }\end{array}$ & ith a new one: freight and ship demand \\
\hline $\begin{array}{l}\text { 3.2.2 Analyze Ships Pricing (chartering, new vs. } \\
\text { secondhand) }\end{array}$ & $\begin{array}{l}\text { The activities of this process will be upd } \\
\text { analysis using AI techniques. }\end{array}$ & ith a new one: ships pricing \\
\hline Devil's quadrangle & & \\
\hline & 02 Assessment of ship risks using fuzzy logic & \\
\hline Prerequisites & KPIs & \\
\hline $\begin{array}{l}\text { - Create a Big Data Warehouse (BDWH) } \\
\text { - Analysis of BDWH using AI techniques } \\
\text { - AI experts team }\end{array}$ & $\begin{array}{l}\text { - Number of days of improvement in the } \\
\text { - Percentage of improvement on ratio co }\end{array}$ & $\begin{array}{l}\text { ion process } \\
\text { g old process/cost using new process }\end{array}$ \\
\hline
\end{tabular}

Figure A6. Assessment of ship risks using fuzzy logic data sheet.

\begin{tabular}{|l|l|}
\hline $\begin{array}{l}\text { Source: Literature review } \\
\text { Other industry app }\end{array}$ & \multicolumn{2}{|l}{} \\
\hline 2.03 Pricing market prediction & \\
\hline Using AI techniques, identify market trends on pricing & $\begin{array}{l}\text { The liner terms will be now obtained looking to AI analysis results as well as to the leg- } \\
\text { acy activities. }\end{array}$ \\
\hline Impacted processes & 4.2.3 Obtain Optimal Liner Terms
\end{tabular}

Figure A7. Cont. 


\begin{tabular}{|l|l|l|}
\hline Devil's quadrangle \\
\hline \multicolumn{1}{|c|}{} \\
\hline
\end{tabular}

Figure A7. Pricing market prediction data sheet.

\begin{tabular}{|c|c|}
\hline \multicolumn{2}{|l|}{$\begin{array}{l}\text { Source: Literature review } \\
\text { Other industry app }\end{array}$} \\
\hline \multicolumn{2}{|c|}{ 2.04 Route optimization via $\mathrm{AI}$ analysis of client information } \\
\hline \multicolumn{2}{|c|}{ Analysis of routes and containers used by a client to reinforce or decrease routes } \\
\hline \multicolumn{2}{|c|}{\begin{tabular}{|l|l|} 
Impacted processes &
\end{tabular}} \\
\hline 2.5.2 Analyze Route Operational Results & $\begin{array}{l}\text { The activities of this process will be updated with a new one: route operational analysis } \\
\text { using AI techniques. }\end{array}$ \\
\hline \multicolumn{2}{|l|}{ Devil's quadrangle } \\
\hline & $\begin{array}{l}4 \text { Route optimization via Al analysis of client } \\
\text { information }\end{array}$ \\
\hline Prerequisites & KPIs \\
\hline $\begin{array}{l}\text { - Create a Big Data Warehouse (BDWH) } \\
\text { - Analysis of BDWH using AI techniques } \\
\text { - AI experts team }\end{array}$ & $\begin{array}{l}\text { - Percentage of decrease on unattended demand on time due to demand peaks } \\
\text { - Percentage of decrease on overcapacity due to demand valleys } \\
\text { - Number of optimized routes } \\
\text { - Percentage of improvement on ratio cost using old process/cost using new process }\end{array}$ \\
\hline
\end{tabular}

Figure A8. Route optimization via AI analysis of client information data sheet.

\begin{tabular}{|l|l|}
\hline \multicolumn{2}{|l|}{ Source: Existing maritime app } \\
\hline 2.05 Client offering optimization via AI analysis of client information \\
\hline Analysis of routes and containers used by a client for clients offering customization \\
\hline Impacted processes & \\
\hline $\begin{array}{l}\text { 4.2.2 BIS Analysis of Liner Terms Based on AI } \\
\text { Analysis of Client Information }\end{array}$ & $\begin{array}{l}\text { New process that needs to be added to the model in order to include the activities de- } \\
\text { rived from this application. }\end{array}$ \\
\hline Devil's quadrangle & \\
\hline
\end{tabular}

Figure A9. Cont. 


\begin{tabular}{|c|c|}
\hline & $\begin{array}{l}\text { 2.05 Client offering optimization via } \mathrm{Al} \text { analysis of } \\
\text { client information }\end{array}$ \\
\hline Prerequisites & KPIs \\
\hline $\begin{array}{l}\text { - Create a Big Data Warehouse (BDWH) } \\
\text { - Analysis of BDWH using AI techniques } \\
\text { - AI experts team }\end{array}$ & $\begin{array}{l}\text { - Percentage of decrease on unattended demand on time due to demand peaks } \\
\text { - Percentage of decrease on overcapacity due to demand valleys } \\
\text { - Percentage of improvement on customer satisfaction } \\
\text { - Percentage of improvement on ratio cost using old process/cost using new process }\end{array}$ \\
\hline
\end{tabular}

Figure A9. Client offering optimization via AI analysis of client information data sheet.

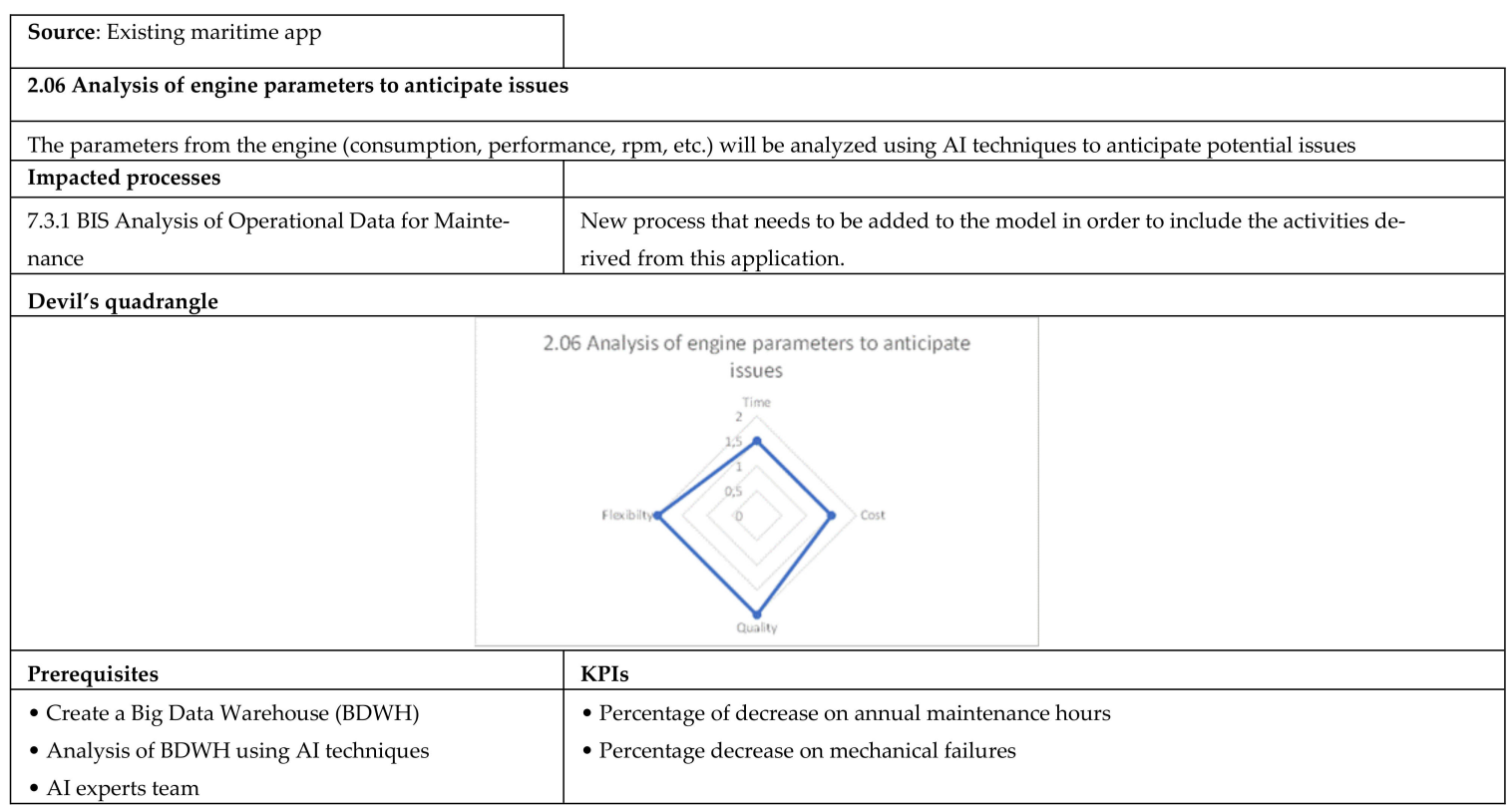

Figure A10. Analysis of engine parameters to anticipate issues data sheet.

\begin{tabular}{|l|l|}
\hline \multicolumn{2}{|l|}{ Source: Existing maritime app } \\
\hline 2.07 Route optimization via AI analysis of operational information \\
\hline $\begin{array}{l}\text { Analysis of routes using AI on operational data (weather, sea conditions, traffic, online port conditions (costs, bunkering, delays, etc.), changes of } \\
\text { crews, etc.) to optimize routes }\end{array}$ \\
\hline Impacted processes & $\begin{array}{l}\text { The activities of this process will be updated with a new one: route operational analy- } \\
\text { sis using AI techniques. }\end{array}$ \\
\hline 2.5.2 Analyze Route Operational Results & \\
\hline Devil's quadrangle & \\
\hline
\end{tabular}

Figure A11. Cont. 


\begin{tabular}{|l|l|}
\hline Prerequisites & KPIs \\
\hline - Create a Big Data Warehouse (BDWH) & $\bullet$ Percentage of decrease in human errors \\
- Analysis of BDWH using AI techniques & $\bullet$ Crew cost decrease \\
- AI experts team & $\begin{array}{l}\text { Percentage of improvement in ratio space for cargo-space for crew } \\
\end{array}$ \\
\hline
\end{tabular}

Figure A11. Route optimization via AI analysis of operational information data sheet.

\begin{tabular}{|c|c|c|}
\hline Source: Existing maritime app & & \\
\hline \multicolumn{3}{|l|}{ 2.08 Process optimization and reengineering using AI } \\
\hline \multicolumn{3}{|c|}{ Analysis based on $\mathrm{AI}$ of the outcomes from every process in the organization to optimize and redesign them } \\
\hline \multicolumn{3}{|c|}{\begin{tabular}{l|l} 
Impacted processes & \\
\end{tabular}} \\
\hline 12.2.3 Manage Business Processes Performance & \multicolumn{2}{|c|}{$\begin{array}{l}\text { The activities of this process will be updated with a new one: business } \\
\text { process analysis using AI techniques. }\end{array}$} \\
\hline 12.2.4 Improve Business Processes Model & \multicolumn{2}{|c|}{$\begin{array}{l}\text { The activities of this process will be updated with a new } \\
\text { one: business process improvement options analysis using } \\
\text { AI techniques. }\end{array}$} \\
\hline \multicolumn{3}{|l|}{ Devil's quadrangle } \\
\hline & \multicolumn{2}{|c|}{$\begin{array}{l}\text { 2.08 Process optimization and reengineering } \\
\text { using } \mathrm{Al}\end{array}$} \\
\hline Prerequisites & \multicolumn{2}{|l|}{ KPIs } \\
\hline $\begin{array}{l}\text { - Create a Data Warehouse for process performance metrics (PPDW) } \\
\text { - Analysis of PPWH using AI techniques } \\
\text { - AI experts team }\end{array}$ & \multicolumn{2}{|c|}{$\begin{array}{l}\text { - Percentage of reduction on route operational costs } \\
\text { - Percentage of improvement on ratio efficiency using old process/ efficiency } \\
\text { using new process } \\
\text { - Percentage of improvement on customer satisfaction }\end{array}$} \\
\hline
\end{tabular}

Figure A12. Process optimization and reengineering using AI data sheet.

\begin{tabular}{|c|c|c|}
\hline \multicolumn{3}{|l|}{ Source: Existing maritime app } \\
\hline \multicolumn{3}{|l|}{ 2.09 Freight rate optimization } \\
\hline \multicolumn{3}{|c|}{ Analysis of internal and external data using AI techniques for determine the optimal freight rate } \\
\hline \multicolumn{3}{|c|}{\begin{tabular}{l|l} 
Impacted processes & \\
\end{tabular}} \\
\hline 4.2.3 Obtain Optimal Liner Terms & $\begin{array}{l}\text { The liner terms will be now obtai } \\
\text { acy activities. }\end{array}$ & to AI analysis results as well as to the leg- \\
\hline \multicolumn{3}{|l|}{ Devil's quadrangle } \\
\hline & 2.09 Freight rate optimization & \\
\hline Prerequisites & \multicolumn{2}{|c|}{ KPIs } \\
\hline $\begin{array}{l}\text { - Create a Big Data Warehouse (BDWH) } \\
\text { - Analysis of BDWH using AI techniques } \\
\text { - AI experts team }\end{array}$ & \multicolumn{2}{|c|}{$\begin{array}{l}\text { - Percentage of improvement in ratio space for cargo-space for crew } \\
\text { - Percentage of improvement on end-of-year financial results }\end{array}$} \\
\hline
\end{tabular}

Figure A13. Freight rate optimization data sheet. 


\begin{tabular}{|c|c|c|}
\hline \multicolumn{3}{|l|}{ Source: Existing maritime app } \\
\hline \multicolumn{3}{|l|}{ 2.10 Fleet dimensioning optimization } \\
\hline \multicolumn{3}{|c|}{$\begin{array}{l}\text { Analysis of internal and external data using AI techniques for determine the optimal use of the existing fleet as well as improving fleet dimension- } \\
\text { ing process }\end{array}$} \\
\hline \multicolumn{3}{|c|}{$\begin{array}{l}\text { Impacted processes } \\
\end{array}$} \\
\hline 3.1.1 Obtain Fleet Operational Data & $\begin{array}{l}\text { This process will change since the } \\
\text { order to propose options regardin }\end{array}$ & $\begin{array}{l}\text { nal data will be treated using AI techniques in } \\
\text { t. }\end{array}$ \\
\hline 3.1.2 Obtain Route Operational Data & $\begin{array}{l}\text { This process will change since the } \\
\text { techniques in order to propose opt }\end{array}$ & $\begin{array}{l}\text { nal data will be treated using AI } \\
\text { arding the routes. }\end{array}$ \\
\hline 3.1.3 Obtain Customers Demand Data & $\begin{array}{l}\text { This process will change since the } \\
\text { to forecast customer demand. }\end{array}$ & nal data will be treated using AI techniques in order \\
\hline 3.1.4 Design Fleet Deployment Plan & $\begin{array}{l}\text { The deployment plan options wil } \\
\text { option. }\end{array}$ & ough the AI tool to help in the decision of the best \\
\hline 3.1.5 Maintain Fleet Deployment Plan & $\begin{array}{l}\text { Results will be compared to the A } \\
\text { the AI tool). }\end{array}$ & ne in order to tune both (fleet deployment plan and \\
\hline \multicolumn{3}{|l|}{ Devil's quadrangle } \\
\hline & 2.10 Fleet dimensioning optimization & \\
\hline Prerequisites & \multicolumn{2}{|l|}{ KPIs } \\
\hline $\begin{array}{l}\text { - Create a Big Data Warehouse (BDWH) } \\
\text { - Analysis of BDWH using AI techniques } \\
\text { - AI experts team }\end{array}$ & \multicolumn{2}{|c|}{$\begin{array}{l}\text { - Percentage of improvement in ratio space for cargo space for crew } \\
\text { - Percentage of improvement on end-of-year financial results }\end{array}$} \\
\hline
\end{tabular}

Figure A14. Fleet dimensioning optimization data sheet.

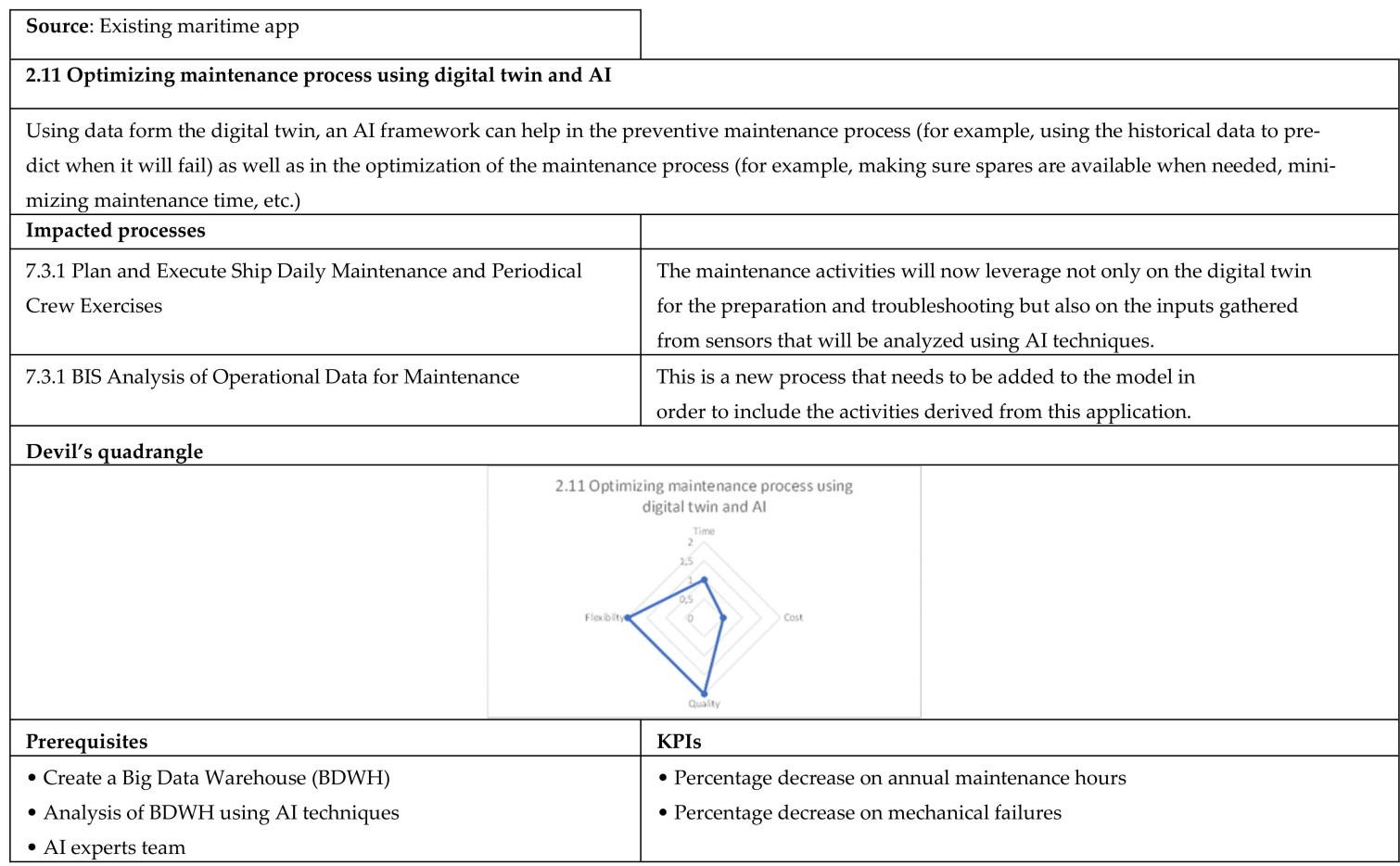

Figure A15. Optimizing maintenance process using digital twin and AI data sheet. 


\begin{tabular}{|c|c|}
\hline \multicolumn{2}{|l|}{ Source: Existing maritime app } \\
\hline \multicolumn{2}{|c|}{2.12 Conversational virtual assistance for helping seafarers in day-to-day activities } \\
\hline \multicolumn{2}{|c|}{$\begin{array}{l}\text { Development of a virtual assistance (Alexa type) that combines the use of AI techniques to help seafarers in daily activities (reporting of weather } \\
\text { conditions, recommendation of routes, gathering data of engine, etc.) }\end{array}$} \\
\hline \multicolumn{2}{|c|}{\begin{tabular}{l|l|l} 
Impacted processes & \\
\end{tabular}} \\
\hline 6.1.5 Charge Ship & $\begin{array}{l}\text { The process needs to integrate the AI virtual assistance in its activities not only on trou- } \\
\text { bleshooting actions but also for providing inputs and executing orders on demand. }\end{array}$ \\
\hline 6.2.1 Unberth Ship & $\begin{array}{l}\text { The process needs to integrate the AI virtual assistance in its activities not } \\
\text { only on troubleshooting actions but also for providing inputs and execut- } \\
\text { ing orders on demand. }\end{array}$ \\
\hline 6.2.2 Sea Voyage & $\begin{array}{l}\text { The process needs to integrate the AI virtual assistance in its activities not only on trouble- } \\
\text { shooting actions but also for providing inputs and executing orders on demand. }\end{array}$ \\
\hline 6.2.6 Berth Ship & $\begin{array}{l}\text { The process needs to integrate the AI virtual assistance in its activities not only on trouble- } \\
\text { shooting actions but also for providing inputs and executing orders on demand. }\end{array}$ \\
\hline 6.3.4 Unload Ship & $\begin{array}{l}\text { The process needs to integrate the AI virtual assistance in its activities not only on trouble- } \\
\text { shooting actions but also for providing inputs and executing orders on demand. }\end{array}$ \\
\hline $\begin{array}{l}\text { 7.3.1 Plan and Execute Ship Daily Maintenance and } \\
\text { Periodical Crew Exercises }\end{array}$ & $\begin{array}{l}\text { The main impact will be in the execution of the maintenance, since this tool will improve the } \\
\text { technician diagnosis and maintenance. }\end{array}$ \\
\hline \multicolumn{2}{|l|}{ Devil's quadrangle } \\
\hline & $\begin{array}{l}\text { 2.12 Conversational virtual assistance for helping } \\
\text { seafarers in day-to-day activities }\end{array}$ \\
\hline Prerequisites & KPIs \\
\hline $\begin{array}{l}\text { - Development of an IoT network on board } \\
\text { - Analysis of IoT data using AI techniques } \\
\text { - AI experts team } \\
\text { - Integration with a conversational virtual assistance } \\
\text { - Development of an AI human interaction framework }\end{array}$ & $\begin{array}{l}\text { - Percentage of decrease in human errors } \\
\text { - Percentage of reduction on costs of the activities (including crew costs and SW/HW costs) }\end{array}$ \\
\hline
\end{tabular}

Figure A16. Conversational virtual assistance for helping seafarers in day-to-day activities data sheet.

\begin{tabular}{|l|l|}
\hline \multicolumn{2}{|l|}{ Source: Existing maritime app } \\
\cline { 1 - 2 } 2.13 Analysis of ship structure images to anticipate issues \\
\hline $\begin{array}{l}\text { The images from ships (hull, hatches, cranes, etc.) will be analyzed using AI techniques to anticipate potential issues (corrosion, coating issues, } \\
\text { welding problems, etc.) }\end{array}$ \\
\hline Impacted processes & $\begin{array}{l}\text { This is a new process that needs to be added to the model in order to include the ac- } \\
\text { tivities derived from this application. }\end{array}$ \\
\hline 7.3.1 BIS Capture and Analysis of Ship Structure Image & $\begin{array}{l}\text { The maintenance activities will now leverage on the images for the } \\
\text { preparation and troubleshooting that will be analyzed using AI tech- } \\
\text { niques. }\end{array}$ \\
\hline $\begin{array}{l}\text { 7.3.1 Plan and Execute Ship Daily Maintenance and Peri- } \\
\text { odical Crew Exercises }\end{array}$ & \\
\hline Devil's quadrangle &
\end{tabular}

Figure A17. Cont. 


\begin{tabular}{|l|l|}
\hline \multicolumn{2}{|c|}{2.13 Analysis of ship structure images to } \\
anticipate issues
\end{tabular}

Figure A17. Analysis of ship structure images to anticipate issues data sheet.

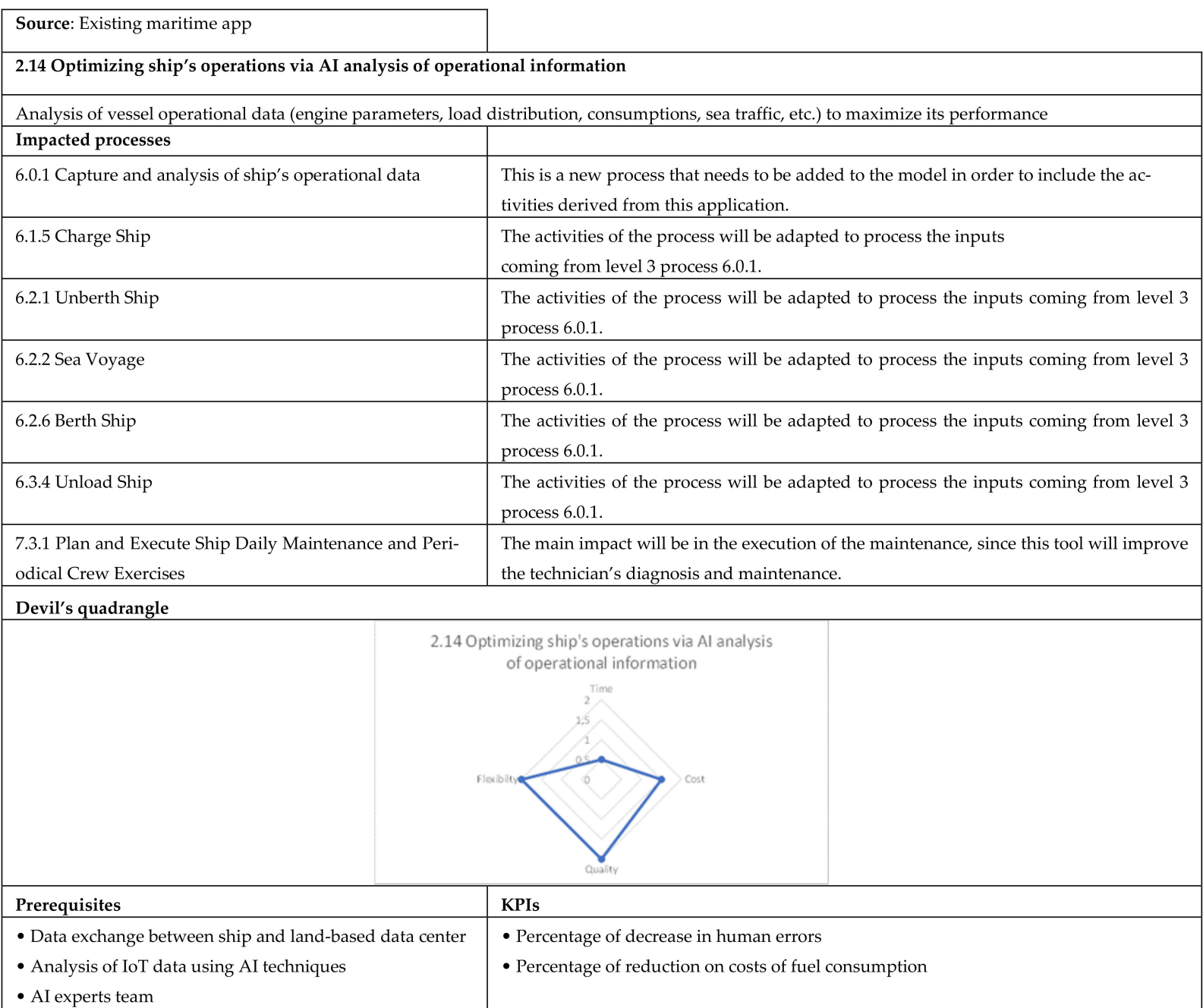

Figure A18. Optimizing ship's operations via AI analysis of operational information data sheet.

\begin{tabular}{|l|l|}
\hline Source: Existing maritime app & \\
\hline $2.15 \mathrm{AI}$ applied to cybersecurity & \\
\hline Use of neuronal networks to detect and prevent cyberattacks \\
\hline Impacted processes & \\
\hline
\end{tabular}

Figure A19. Cont. 


\begin{tabular}{|l|l|}
\hline 11.3.3 Control IT Security and Risks & $\begin{array}{l}\text { The activities will be highly impacted, since the integration of the AI technology will } \\
\text { require a full review of cybersecurity procedures. }\end{array}$ \\
\hline Devil's quadrangle & 2.15 Al applied to cybersecurity \\
\hline \multicolumn{3}{|c|}{} \\
\hline
\end{tabular}

Figure A19. AI applied to cybersecurity data sheet.

\begin{tabular}{|c|c|c|}
\hline Source: Existing maritime app & & \\
\hline \multicolumn{3}{|l|}{ 2.16 AI applied to data management and clean } \\
\hline \multicolumn{3}{|c|}{ Use of AI to enhance dashboards, enhance data quality, detect patterns on information at the DWH, populate DWH with relevant information } \\
\hline \multicolumn{3}{|c|}{\begin{tabular}{|l|l|} 
Impacted processes & \\
\end{tabular}} \\
\hline 2.1.4 Generate Global Economy Situation Model & \multicolumn{2}{|c|}{$\begin{array}{l}\text { The activities of this process will need to apply AI to the data obtained here for the final } \\
\text { goal of the process group. }\end{array}$} \\
\hline 2.3.7 Generate Ports Analysis Report & \multicolumn{2}{|c|}{$\begin{array}{l}\text { The activities of this process will need to apply AI to the data obtained here } \\
\text { for the final goal of the process group. }\end{array}$} \\
\hline 3.1.4 Design Fleet Deployment Plan & \multicolumn{2}{|c|}{$\begin{array}{l}\text { The activities of this process will need to apply AI to the data obtained here for the final goal } \\
\text { of the process group. }\end{array}$} \\
\hline $\begin{array}{l}\text { 5.3.2 Populate and Manage Customer's Information } \\
\text { DWH }\end{array}$ & \multicolumn{2}{|c|}{$\begin{array}{l}\text { The population of the DWH will strongly leverage on the AI application for enhancing the data } \\
\text { quality. }\end{array}$} \\
\hline 9.6.2 Manage Employees Data & \multicolumn{2}{|c|}{$\begin{array}{l}\text { The activities of this process will need to apply AI to the data obtained here for the final goal } \\
\text { of the process group. }\end{array}$} \\
\hline \multicolumn{3}{|l|}{ Devil's quadrangle } \\
\hline \multicolumn{3}{|c|}{ 2.16 Al applied to data management and clean } \\
\hline Prerequisites & \multicolumn{2}{|l|}{ KPIs } \\
\hline $\begin{array}{l}\text { - Create a Big Data Warehouse (BDWH) } \\
\text { - Analysis of BDWH using AI techniques } \\
\text { - AI experts team }\end{array}$ & \multicolumn{2}{|c|}{$\begin{array}{l}\text { - Number of days of improvement in the decision process } \\
\text { - Percentage of reduction of data inaccuracy } \\
\text { - Percentage of reduction of failure on data population } \\
\text { - Percentage of maintenance resources costs reductions }\end{array}$} \\
\hline
\end{tabular}

Figure A20. AI applied to data management and clean data sheet. 


\begin{tabular}{|c|c|c|}
\hline \multicolumn{3}{|l|}{ Source: Existing maritime app } \\
\hline \multicolumn{3}{|c|}{ 2.17 AI applied to competitors tracking and monitoring } \\
\hline \multicolumn{3}{|c|}{ Use of AI to monitor actions and performance of competitors } \\
\hline \multicolumn{3}{|c|}{\begin{tabular}{|l|l} 
Impacted processes & \\
\end{tabular}} \\
\hline 2.2.1 Analyze Competitors Routes & \multicolumn{2}{|c|}{$\begin{array}{l}\text { The activities of this process will be adapted to accommodate the use of AI in such a way } \\
\text { that information will flow constantly instead of the current batches of information. }\end{array}$} \\
\hline 2.2.2 Analyze Competitors Finance & \multicolumn{2}{|c|}{$\begin{array}{l}\text { The activities of this process will be adapted to accommodate the use of AI } \\
\text { in such a way that information will flow constantly instead of the current } \\
\text { batches of information. }\end{array}$} \\
\hline 2.2.3 Analyze Competitors Sales & \multicolumn{2}{|c|}{$\begin{array}{l}\text { The activities of this process will be adapted to accommodate the use of AI in such a way that } \\
\text { information will flow constantly instead of the current batches of information. }\end{array}$} \\
\hline 2.2.4 Analyze Competitors Clients & \multicolumn{2}{|c|}{$\begin{array}{l}\text { The activities of this process will be adapted to accommodate the use of AI in such a way that } \\
\text { information will flow constantly instead of the current batches of information. }\end{array}$} \\
\hline \multicolumn{3}{|l|}{ Devil's quadrangle } \\
\hline & $\begin{array}{l}\text { 2.17 Al applied to competitors tracking and } \\
\text { monitoring }\end{array}$ & \\
\hline Prerequisites & \multicolumn{2}{|l|}{ KPIs } \\
\hline $\begin{array}{l}\text { - Create a Big Data Warehouse (BDWH) } \\
\text { - Analysis of BDWH using AI techniques } \\
\text { - AI experts team }\end{array}$ & \multicolumn{2}{|c|}{$\begin{array}{l}\text { - Number of days of improvement in the decision process } \\
\text { - Percentage reduction in customers' churn } \\
\text { - Percentage of increase on new customers/business }\end{array}$} \\
\hline
\end{tabular}

Figure A21. AI applied to competitors tracking and monitoring data sheet.

\begin{tabular}{|c|c|c|}
\hline Source: Existing maritime app & & \\
\hline \multicolumn{3}{|c|}{ 2.18 AI applied to business partners tracking and monitoring } \\
\hline \multicolumn{3}{|c|}{ Use of AI to monitor actions and performance of business partners } \\
\hline \multicolumn{3}{|c|}{\begin{tabular}{|l|l} 
Impacted processes & \\
\end{tabular}} \\
\hline $\begin{array}{l}\text { 4.3.2 Design Alliance Programs and Plans for Man- } \\
\text { aging Relationships }\end{array}$ & \multicolumn{2}{|c|}{$\begin{array}{l}\text { The activities of this process will be adapted to accommodate the use of AI in such a way } \\
\text { that information will flow constantly instead of the current batches of information. }\end{array}$} \\
\hline \multicolumn{3}{|l|}{ Devil's quadrangle } \\
\hline & $\begin{array}{l}8 \text { Al applied to business partners tracking and } \\
\text { monitoring }\end{array}$ & \\
\hline Prerequisites & \multicolumn{2}{|c|}{ KPIs } \\
\hline $\begin{array}{l}\text { - Create a Big Data Warehouse (BDWH) } \\
\text { - Analysis of BDWH using AI techniques } \\
\text { - AI experts team }\end{array}$ & \multicolumn{2}{|c|}{$\begin{array}{l}\text { - Number of days of improvement in the decision process } \\
\text { - Percentage of increase on partners' efficiency }\end{array}$} \\
\hline
\end{tabular}

Figure A22. AI applied to business partners tracking and monitoring data sheet. 


\begin{tabular}{|c|c|c|}
\hline \multicolumn{3}{|l|}{ Source: Existing maritime app } \\
\hline \multicolumn{3}{|c|}{$2.19 \mathrm{AI}$ applied to providers tracking and monitoring } \\
\hline \multicolumn{3}{|c|}{ Analysis performance by provider using AI techniques to better define the relationship } \\
\hline \multicolumn{3}{|c|}{\begin{tabular}{|l|l|} 
Impacted processes & \\
\end{tabular}} \\
\hline 10.5.2 Manage Procurement & $\begin{array}{l}\text { The activities of this process will be ad } \\
\text { that information will flow constantly in }\end{array}$ & $\begin{array}{l}\text { I to accommodate the use of AI in such a way } \\
\text { of the current batches of information. }\end{array}$ \\
\hline \multicolumn{3}{|l|}{ Devil's quadrangle } \\
\hline & $\begin{array}{l}\text { 2.19 Al applied to providers tracking and } \\
\text { monitoring }\end{array}$ & \\
\hline Prerequisites & \multicolumn{2}{|l|}{ KPIs } \\
\hline $\begin{array}{l}\text { - Create a Big Data Warehouse (BDWH) } \\
\text { - Analysis of BDWH using AI techniques } \\
\text { - AI experts team }\end{array}$ & \multicolumn{2}{|c|}{$\begin{array}{l}\text { - Number of days of improvement in the decision process } \\
\text { - Percentage of increase on providers' efficiency }\end{array}$} \\
\hline
\end{tabular}

Figure A23. AI applied to providers tracking and monitoring data sheet.

\begin{tabular}{|c|c|c|}
\hline \multicolumn{3}{|l|}{ Source: Existing maritime app } \\
\hline \multicolumn{3}{|l|}{$2.20 \mathrm{AI}$ applied to 3 parties route prediction } \\
\hline \multicolumn{3}{|c|}{ Use of AI to monitor and predict route of other vessels around } \\
\hline \multicolumn{3}{|c|}{\begin{tabular}{|l|l} 
Impacted processes & \\
\end{tabular}} \\
\hline 6.2.2 Sea Voyage & \multicolumn{2}{|c|}{$\begin{array}{l}\text { The activities related with navigation in this process will need to take into account the } \\
\text { inputs of this tool and make it part of the navigation decision process, acting as a backup } \\
\text { for AIS when not available. }\end{array}$} \\
\hline \multicolumn{3}{|l|}{ Devil's quadrangle } \\
\hline & 2.20 Al applied to 3 parties route prediction & \\
\hline Prerequisites & \multicolumn{2}{|l|}{ KPIs } \\
\hline $\begin{array}{l}\text { - Create a Big Data Warehouse }(\mathrm{BDWH}) \\
\text { - Analysis of BDWH using AI techniques } \\
\text { - AI experts team }\end{array}$ & \multicolumn{2}{|c|}{$\begin{array}{l}\text { - Percentage of decrease on incidents/accidents } \\
\text { - Percentage of reduction of cost coming incidents/accidents }\end{array}$} \\
\hline
\end{tabular}

Figure A24. AI applied to 3 parties route prediction data sheet.

\begin{tabular}{|l|l|}
\hline Source: Existing maritime app & \multicolumn{2}{|l|}{} \\
\hline 2.21 Using AI to enhance navigation safety \\
\hline Analysis on vessel data to anticipate dangerous scenarios based on AI \\
\hline Impacted processes & \\
\hline 6.2 .2 Sea Voyage & $\begin{array}{l}\text { The activities related with navigation in this process will need to take into account the } \\
\text { inputs of this tool and make it part of the navigation decision process. }\end{array}$ \\
\hline Devil's quadrangle & \\
\hline
\end{tabular}

Figure A25. Cont. 


\begin{tabular}{|l|l|}
\hline \multicolumn{1}{|l|}{} \\
\hline
\end{tabular}

Figure A25. Using AI to enhance navigation safety data sheet.

\begin{tabular}{|c|c|c|}
\hline \multicolumn{3}{|l|}{ Source: Existing maritime app } \\
\hline \multicolumn{3}{|l|}{2.22 Using AI to reduce emissions } \\
\hline \multicolumn{3}{|c|}{ Analysis on vessel data to reduce GHG emissions. Capturing data from vessel, weather, and route to reduce ship's emissions } \\
\hline \multicolumn{3}{|c|}{\begin{tabular}{|l|l|l} 
Impacted processes & \\
\end{tabular}} \\
\hline 6.2.2 Sea Voyage & \multicolumn{2}{|c|}{$\begin{array}{l}\text { The activities related with navigation in this process will need to take into account the } \\
\text { inputs of this tool and make it part of the navigation decision process. }\end{array}$} \\
\hline $\begin{array}{l}\text { 7.3.1 BIS Analysis of Operational Data for Mainte- } \\
\text { nance }\end{array}$ & \multicolumn{2}{|c|}{$\begin{array}{l}\text { This is a new process that, in this case, will provide inputs to the tool for } \\
\text { helping in the decision-making process. }\end{array}$} \\
\hline \multicolumn{3}{|l|}{ Devil's quadrangle } \\
\hline & $2.22 \mathrm{Using}$ Al to reduce emissions & \\
\hline Prerequisites & \multicolumn{2}{|l|}{ KPIs } \\
\hline $\begin{array}{l}\text { - Create a Big Data Warehouse (BDWH) } \\
\text { - Analysis of BDWH using AI techniques } \\
\text { - AI experts team }\end{array}$ & \multicolumn{2}{|c|}{$\begin{array}{l}\text { - Percentage of decrease on annual maintenance hours } \\
\text { - Percentage of reduction of cost coming from penalties }\end{array}$} \\
\hline
\end{tabular}

Figure A26. Using AI to reduce emissions data sheet.

\begin{tabular}{|l|l|}
\hline Source: Literature review & \multicolumn{2}{|l|}{} \\
\hline 3.01 Big data algorithm for collision avoidance & $\begin{array}{l}\text { The activities related with navigation in this } \\
\text { tion, calculating the risk-degree of collision of ships and determining the degree of immediate danger of ships for avoidance of shipwreck }\end{array}$ \\
\hline Impacted processes & $\begin{array}{l}\text { process will need to take into account the } \\
\text { inputs of this tool and make it part of the } \\
\text { navigation decision process. }\end{array}$ \\
\hline 6.2.2 Sea Voyage & \\
\hline Devil's quadrangle & \\
\hline
\end{tabular}

Figure A27. Cont. 


\begin{tabular}{|c|c|c|}
\hline & Fi.01 Big data algorithm for collision avoidance & \\
\hline Prerequisites & & KPIs \\
\hline $\begin{array}{l}\text { - Create a Big Data Warehouse (BDWH) } \\
\text { - Online capability for AIS/image analysis } \\
\text { - Big Data experts }\end{array}$ & & $\begin{array}{l}\text { - Percentage of decrease in human errors } \\
\text { - Percentage of decrease on incidents/accidents } \\
\text { - Percentage of reduction of cost related to inci- } \\
\text { dents/accidents }\end{array}$ \\
\hline
\end{tabular}

Figure A27. Big data algorithm for collision avoidance data sheet.

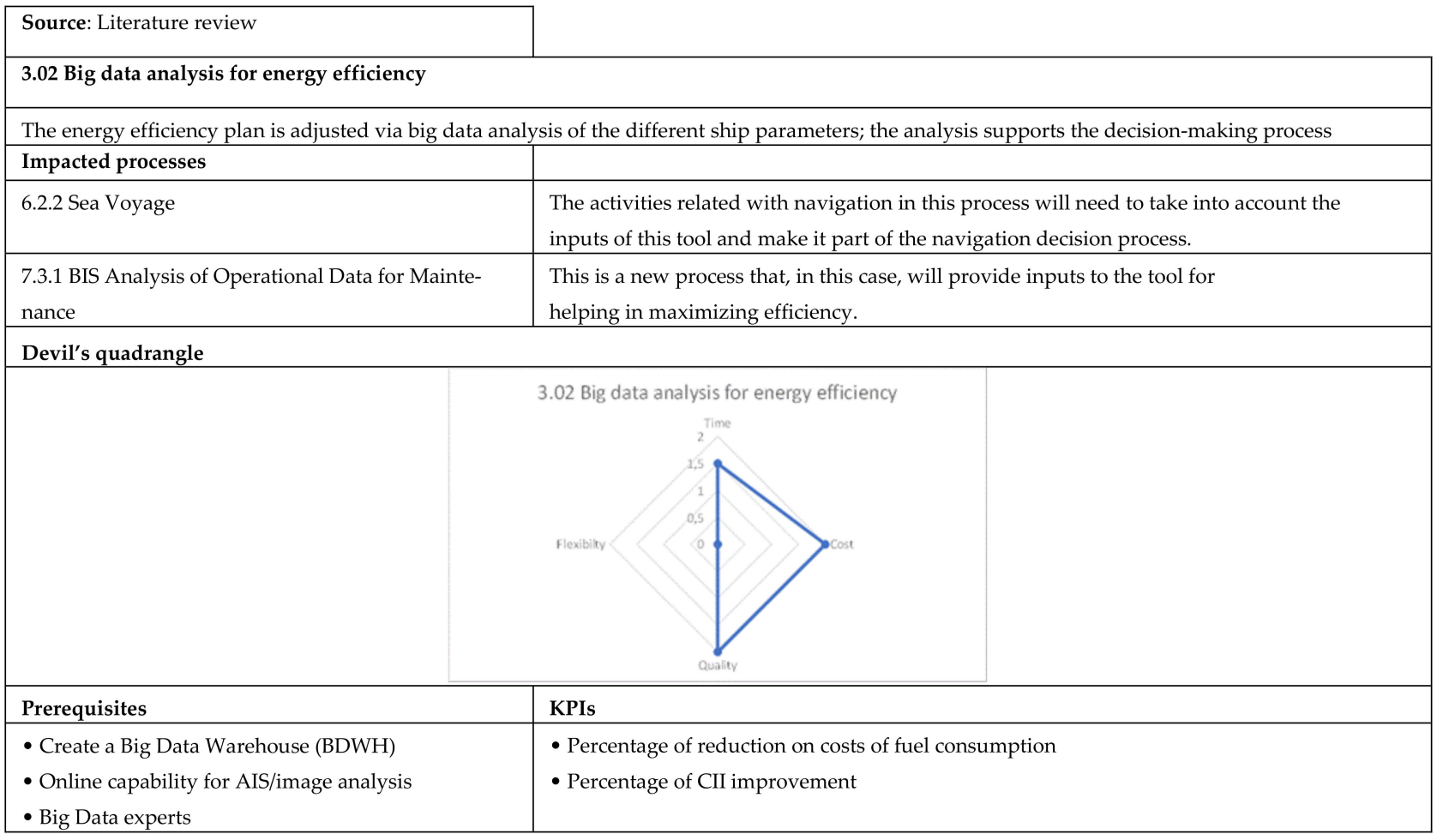

Figure A28. Big data analysis for energy-efficiency data sheet.

\begin{tabular}{|l|l|}
\hline \multicolumn{2}{|l|}{ Source: Existing maritime app } \\
\hline 3.03 Analysis of data on consumption and emissions for bunkering selection \\
\hline $\begin{array}{l}\text { Data on consumption, NOx, SOx, engine failures, etc. will be stored and analyzed in order to evaluate the effect of bunkering providers in ship } \\
\text { performance }\end{array}$ \\
\hline Impacted processes & $\begin{array}{l}\text { This is a new process that, in this case, it will provide inputs to the tool for helping in re- } \\
\text { ducing costs and improve ship efficiency, both relative to enhance bunkering }\end{array}$ \\
\hline $\begin{array}{l}\text { 7.3.1 BIS Analysis of Operational Data for Mainte- } \\
\text { nance }\end{array}$ & \\
\hline Devil's quadrangle
\end{tabular}

Figure A29. Cont. 


\begin{tabular}{|l|l|}
\hline \multicolumn{1}{|l|}{} & $\begin{array}{c}3.03 \text { Analysis of data on consumption and } \\
\text { emissions for bunkering selection }\end{array}$ \\
\hline Prerequisites & KPIs \\
\hline - Create a Big Data Warehouse (BDWH) & $\begin{array}{l}\text { - Percentage of reduction on maintenance costs } \\
\text { - Percentage of reduction on costs of fuel consumption }\end{array}$ \\
\hline
\end{tabular}

Figure A29. Analysis of data on consumption and emissions for bunkering selection data sheet.

\begin{tabular}{|c|c|c|}
\hline \multicolumn{3}{|l|}{ Source: Existing maritime app } \\
\hline \multicolumn{3}{|l|}{ 3.04 ISPS security levels } \\
\hline \multicolumn{3}{|c|}{$\begin{array}{l}\text { Gather data from different sources (news updates, radio communications, homeland security alerts, etc.) to better-quality risks related to ISPS } \\
\text { security levels }\end{array}$} \\
\hline \multicolumn{3}{|c|}{\begin{tabular}{l|l} 
Impacted processes & \\
\end{tabular}} \\
\hline $\begin{array}{l}\text { 9.8.5 Define Safety Framework (Goals, KPIs, Train- } \\
\text { ing, Drills, etc.) }\end{array}$ & $\begin{array}{l}\text { The inputs from previous tas } \\
\text { to anticipate security issues. }\end{array}$ & the DWH for a big data analysis in order \\
\hline 9.8.6 Deploy and Monitor Safety Framework & $\begin{array}{l}\text { The inputs from previous tas } \\
\text { ysis in order to anticipate sec }\end{array}$ & the DWH for a big data anal- \\
\hline \multicolumn{3}{|l|}{ Devil's quadrangle } \\
\hline & Flexibity 3.04 ISPS security levels & \\
\hline Prerequisites & \multicolumn{2}{|c|}{ KPIs } \\
\hline $\begin{array}{l}\text { - Integration with 3rd parties DB for data collection } \\
\text { - Big Data experts }\end{array}$ & \multicolumn{2}{|c|}{$\begin{array}{l}\text { - Percentage of decrease on security incidents } \\
\text { - Percentage of reduction of cost coming security incidents }\end{array}$} \\
\hline
\end{tabular}

Figure A30. ISPS security levels data sheet.

\begin{tabular}{|l|l|}
\hline \multicolumn{2}{|l|}{ Source: Existing maritime app } \\
\hline 3.05 Big Data for Ship Renewal \\
\begin{tabular}{|l|l|} 
Gather data from different sources (market insights, supply/demand, changes on routes, etc.) to decide the best type of vessel for the market that is \\
coming
\end{tabular} \\
\hline Impacted processes & $\begin{array}{l}\text { The activities of this process will be adapted to accommodate the use of big data tech- } \\
\text { niques in such a way that information will flow constantly instead of the current batches } \\
\text { of information. }\end{array}$ \\
\hline $\begin{array}{l}\text { 3.2.1 Analyze Freight Evolution and Ship Demand } \\
\text { secondhand) }\end{array}$ & $\begin{array}{l}\text { The activities of this process will be adapted to accommodate the use of big } \\
\text { data techniques in such a way that information will flow constantly instead } \\
\text { of the current batches of information. }\end{array}$ \\
\hline $\begin{array}{l}\text { 3.2.3 Analyze Ship Characteristics (ship size, stabil- } \\
\text { ity in different demand conditions, etc.) }\end{array}$ & $\begin{array}{l}\text { The activities of this process will be adapted to accommodate the use of big data techniques in } \\
\text { such a way that information will flow constantly instead of the current batches of information. }\end{array}$ \\
\hline 3.2.4 Analyze Fleet Productivity & $\begin{array}{l}\text { The activities of this process will be adapted to accommodate the use of big data techniques in } \\
\text { such a way that information will flow constantly instead of the current batches of information. }\end{array}$ \\
\hline Devil's quadrangle & \multicolumn{2}{|l}{} \\
\hline
\end{tabular}

Figure A31. Cont. 


\begin{tabular}{|l|l|}
\hline \multicolumn{1}{|l|}{} \\
\hline
\end{tabular}

Figure A31. Big data for ship renewal data sheet.

\begin{tabular}{|c|c|c|}
\hline \multicolumn{3}{|l|}{ Source: Existing maritime app } \\
\hline \multicolumn{3}{|l|}{ 3.06 Big Data for Ship speed controlling } \\
\hline \multicolumn{3}{|c|}{$\begin{array}{l}\text { Adapt and control vessel speed to port conditions: the analysis of historical data together with the information received on port congestion should be applied } \\
\text { to the ship's speed in order to avoid extra consumption }\end{array}$} \\
\hline \multicolumn{3}{|c|}{\begin{tabular}{|l|l} 
Impacted processes & \\
\end{tabular}} \\
\hline 6.2.2 Sea Voyage & $\begin{array}{l}\text { The activities of the process regarding navi } \\
\text { from big data analysis for adjusting route a } \\
\text { crew to decide the best option. }\end{array}$ & $\begin{array}{l}\text { Il need to take into account the inputs coming } \\
\text { either automatically or as optional for the }\end{array}$ \\
\hline \multicolumn{3}{|l|}{ Devil's quadrangle } \\
\hline & F.06 Big Data for Ship speed controlling & \\
\hline Prerequisites & \multicolumn{2}{|l|}{ KPIs } \\
\hline $\begin{array}{l}\text { - Integration with 3rd parties DB for data collection } \\
\text { - Big data experts }\end{array}$ & \multicolumn{2}{|c|}{$\begin{array}{l}\text { - Number of days of improvement in the decision process } \\
\text { - Percentage of reduction on costs of fuel consumption }\end{array}$} \\
\hline
\end{tabular}

Figure A32. Big data for ship speed controlling data sheet.

\begin{tabular}{|l|l|}
\hline \multicolumn{2}{|l|}{ Source: Literature review } \\
\cline { 1 - 2 } 4.01 VR for training & \\
\hline Make use of virtual reality for complex tasks training (bridge, engine, etc.) \\
\hline Impacted processes & $\begin{array}{l}\text { The activities of this process will be adapted to accommodate the use of VR techniques, } \\
\text { including software and hardware. }\end{array}$ \\
\hline 9.3.3 Manage Employees Training & $\begin{array}{l}\text { The main impact will be on the deployment of infrastructure for delivering } \\
\text { the training. }\end{array}$ \\
\hline $\begin{array}{l}\text { 9.4.3 Manage Training On Board } \\
\text { ing, Drills, etc.) }\end{array}$ & \begin{tabular}{l} 
The training and the drills will include the use of VR techniques. \\
\hline Devil's quadrangle
\end{tabular} \\
\hline
\end{tabular}

Figure A33. Cont. 


\begin{tabular}{|l|l|l|}
\hline & \\
\hline Prerequisites & KPIs \\
\hline •VR platform & \begin{tabular}{l}
\hline \\
\hline
\end{tabular} & Percentage of decrease on safety incidents \\
\hline
\end{tabular}

Figure A33. VR for training data sheet.

\begin{tabular}{|c|c|c|}
\hline \multicolumn{3}{|c|}{$\begin{array}{l}\text { Source: Literature review } \\
\text { Existing maritime app }\end{array}$} \\
\hline \multicolumn{3}{|c|}{ 4.02 VR as navigation aid } \\
\hline \multicolumn{3}{|c|}{ Deploy VR solution for helping captain on decision-making process during navigation (access to port, navigation in poor weather conditions, etc.) } \\
\hline \multicolumn{3}{|c|}{\begin{tabular}{|l|l|} 
Impacted processes & \\
\end{tabular}} \\
\hline 6.2.1 Unberth Ship & \multicolumn{2}{|c|}{$\begin{array}{l}\text { The activities of this process will be adapted to accommodate the use of VR techniques so } \\
\text { that the decisions from the crew will be based on the inputs from this tool. }\end{array}$} \\
\hline 6.2.2 Sea Voyage & \multicolumn{2}{|c|}{$\begin{array}{l}\text { The activities of this process will be adapted to accommodate the use of VR } \\
\text { techniques so that the decisions from the crew will be based on the inputs } \\
\text { from this tool. }\end{array}$} \\
\hline 6.2.6 Berth Ship & \multicolumn{2}{|c|}{$\begin{array}{l}\text { The activities of this process will be adapted to accommodate the use of VR techniques so that } \\
\text { the decisions from the crew will be based on the inputs from this tool. }\end{array}$} \\
\hline \multicolumn{3}{|l|}{ Devil's quadrangle } \\
\hline & Flexibity & \\
\hline Prerequisites & \multicolumn{2}{|l|}{ KPIs } \\
\hline - VR platform & \multicolumn{2}{|c|}{$\begin{array}{l}\text { - Percentage of decrease on safety incidents } \\
\text { - Percentage of reduction of costs related to safety incidents }\end{array}$} \\
\hline
\end{tabular}

Figure A34. VR as navigation aid data sheet.

\begin{tabular}{|l|l|}
\hline \multicolumn{2}{|l|}{ Source: Existing maritime app } \\
\hline 4.03 VR for maintenance \\
\hline Integrate VR in on-board maintenance processes, including views of the manuals and inputs from landed personnel such as vendors \\
\hline Impacted processes & \\
\hline $\begin{array}{l}\text { 7.3.1 Plan and Execute Ship Daily Maintenance and } \\
\text { Periodical Crew Exercises }\end{array}$ & Manuals and schemas will now be loaded in the VR tool, allowing quick access to them. \\
\hline Devil's quadrangle
\end{tabular}

Figure A35. Cont. 


\begin{tabular}{|l|l|}
\hline \multicolumn{1}{|c|}{} \\
\hline Prerequisites & KPIs \\
\hline - VR platform & $\begin{array}{l}\text { P Percentage of decrease on safety incidents } \\
\text { Percentage of reduction of maintenance cost }\end{array}$ \\
\hline
\end{tabular}

Figure A35. VR for maintenance data sheet.

\begin{tabular}{|c|c|}
\hline \multicolumn{2}{|l|}{$\begin{array}{l}\text { Source: Literature review } \\
\text { Existing maritime app }\end{array}$} \\
\hline \multicolumn{2}{|l|}{ 5.01 Container tracking } \\
\hline \multicolumn{2}{|l|}{ Implement IoT into containers for tracking purposes } \\
\hline \multicolumn{2}{|l|}{ Impacted processes } \\
\hline 3.3.1 BIS Analyze Containers Capabilities & New process that will include the qualification of containers for these services. \\
\hline 5.1.1 Contact Customer & The contact will move from a user contact to a service contact. \\
\hline 6.1.5 Charge Ship & All the container charging/discharging information will be through the IoT platform. \\
\hline 6.2.2 Sea Voyage & $\begin{array}{l}\text { The IoT platform will be integrated into this process so that it can provide to the customers a } \\
\text { reliable information of time of arrival. }\end{array}$ \\
\hline 6.3.4 Unload Ship & All the container charging/discharging information will be through the IoT platform. \\
\hline $\begin{array}{l}\text { 8.2.1 Sign Multimodal Transportation Merchant Re- } \\
\text { ception Documents }\end{array}$ & $\begin{array}{l}\text { All the container reception/delivery information in a multimodal transport will be through the } \\
\text { IoT platform. }\end{array}$ \\
\hline 8.2.2 Execute Maritime Leg & $\begin{array}{l}\text { The IoT platform will be integrated into this process so that it can provide to the customers a } \\
\text { reliable information of time of arrival. }\end{array}$ \\
\hline $\begin{array}{l}\text { 8.2.3 Sign Multimodal Transportation Merchant De- } \\
\text { livery Documents }\end{array}$ & $\begin{array}{l}\text { All the container reception/delivery information in a multimodal transport will be through the } \\
\text { IoT platform. }\end{array}$ \\
\hline \multicolumn{2}{|l|}{ Devil's quadrangle } \\
\hline & 5.01 Container tracking \\
\hline Prerequisites & KPIs \\
\hline $\begin{array}{l}\text { - IoT integration into containers } \\
\text { - Could/Edge network in the ships }\end{array}$ & $\begin{array}{l}\text { - Percentage of improvement on customer satisfaction } \\
\text { - Percentage of increase in containers' utilization }\end{array}$ \\
\hline
\end{tabular}

Figure A36. Container tracking data sheet.

\begin{tabular}{|l|l|}
\hline \multicolumn{2}{|l|}{ Source: Existing maritime app } \\
\hline 5.02 Optimization of equipment usage \\
\hline \multicolumn{2}{|l|}{ Through IoT monitorization, optimize the use of equipment in order to avoid unnecessary energy consumption } \\
\hline Impacted processes & $\begin{array}{l}\text { This is a new process that will trigger the monitorization of the ship equipment and take } \\
\text { the actions for optimizing their usage. }\end{array}$ \\
\hline 6.2.1 BIS Start Equipment Monitorization & $\begin{array}{l}\text { This is a new process that will end the monitorization of the ship equip- } \\
\text { ment. }\end{array}$ \\
\hline 6.2.6 BIS End Equipment Monitorization & \\
\hline
\end{tabular}

Figure A37. Cont. 


\begin{tabular}{|l|l|}
\hline Devil's quadrangle \\
\hline
\end{tabular}

Figure A37. Optimization of equipment data sheet.

\begin{tabular}{|c|c|c|}
\hline \multicolumn{3}{|l|}{ Source: Existing maritime app } \\
\hline \multicolumn{3}{|l|}{ 5.03 Digital twin for training purposes } \\
\hline \multicolumn{3}{|c|}{ Leverage in the digital twin to develop advanced training to selected crew members } \\
\hline \multicolumn{3}{|c|}{ 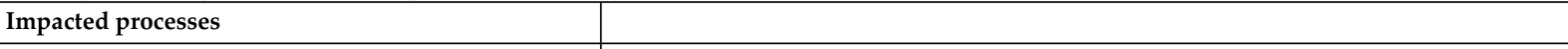 } \\
\hline 9.3.3 Manage Employees Training & \multicolumn{2}{|c|}{ The activities of this process will be adapted to accommodate the use of the digital twin. } \\
\hline 9.4.3 Manage Training On Board & \multicolumn{2}{|c|}{$\begin{array}{l}\text { The activities of this process will be adapted to accommodate the use of the } \\
\text { digital twin. }\end{array}$} \\
\hline $\begin{array}{l}\text { 9.8.5 Define Safety Framework (Goals, KPIs, Train- } \\
\text { ing, Drills, etc.) }\end{array}$ & \multicolumn{2}{|c|}{ The activities of this process will be adapted to accommodate the use of the digital twin. } \\
\hline \multicolumn{3}{|l|}{ Devil's quadrangle } \\
\hline & 5.03 Digital twin for training purposes & \\
\hline Prerequisites & \multicolumn{2}{|l|}{ KPIs } \\
\hline $\begin{array}{l}\text { - Digital twin } \\
\text { - Development of training sessions based on twin }\end{array}$ & \multicolumn{2}{|c|}{$\begin{array}{l}\text { - Percentage of decrease on safety incidents } \\
\text { - Percentage of reduction on training costs }\end{array}$} \\
\hline
\end{tabular}

Figure A38. Digital twin for training purposes data sheet.

Source: Literature review

Existing maritime app

6.01 Cloud/Edge platform

Use of a cloud/edge environment to capture and send/receive information used by the rest of the applications and digital domains Impacted processes

11.6.3 Plan and Manage IT Infrastructure

The management of the infrastructure will need to include new activities in order to interconnect the company's IT management system with the one from the cloud provider.

Devil's quadrangle

Figure A39. Cont. 


\begin{tabular}{|l|l|l|}
\hline \multicolumn{1}{|l|}{} & \\
& \\
\hline
\end{tabular}

Figure A39. Cloud/Edge platform data sheet.

\begin{tabular}{|c|c|}
\hline Source: Existing maritime app & \\
\hline 6.02 Use of SaaS via cloud & \\
\hline Reduce the TCO in SW by the use & \\
\hline Impacted processes & \\
\hline 11.5.2 Define Development Plan & $\begin{array}{l}\text { Decommissioned. This process will not be required for the SaaS since it will be com- } \\
\text { pleted by the vendor. }\end{array}$ \\
\hline 11.5.3 Develop and Test Solution & $\begin{array}{l}\text { Decommissioned. This process will not be required for the SaaS since it will } \\
\text { be completed by the vendor. }\end{array}$ \\
\hline Devil's quadrangle & \\
\hline & Flexbitits cost \\
\hline Prerequisites & KPIs \\
\hline & $\begin{array}{l}\text { - Percentage of reduction of CAPEX-OPEX ratio } \\
\text { - Percentage of reduction of cost coming of SW maintenance }\end{array}$ \\
\hline
\end{tabular}

Figure A40. Use of SaaS via cloud data sheet.

\begin{tabular}{|l|l|}
\hline \multicolumn{2}{|l|}{ Source: Existing maritime app } \\
\cline { 1 - 2 } 6.03 Use of eLearning via cloud \\
\hline Develop training sessions that can be downloaded by the workforce and move the online learning sessions to the cloud \\
\hline Impacted processes & \\
\hline 9.3.3 Manage Employees Training & $\begin{array}{l}\text { The activities of this process will now include the ones for loading updated training } \\
\text { in the cloud. }\end{array}$ \\
\hline 9.4.3 Manage Training On Board & $\begin{array}{l}\text { The activities of this process will now include the ones for loading up- } \\
\text { dated training in the cloud. }\end{array}$ \\
\hline $\begin{array}{l}\text { 9.8.5 Define Safety Framework (Goals, KPIs, Training, } \\
\text { Drills, etc.) }\end{array}$ & The KPIs will be updated to include performance management KPIs on these courses. \\
\hline Devil's quadrangle & \\
\hline
\end{tabular}

Figure A41. Cont. 


\begin{tabular}{|c|c|}
\hline & Qualty \\
\hline Prerequisites & KPIs \\
\hline $\begin{array}{l}\text { - Development of the eLearning platform or negotiate with } \\
\text { an eLearning provider } \\
\text { - HW for the workforce }\end{array}$ & $\begin{array}{l}\text { - Percentage of reduction in training costs } \\
\text { - Percentage of increase in training on time }\end{array}$ \\
\hline
\end{tabular}

Figure A41. Use of eLearning via cloud data sheet.

\begin{tabular}{|c|c|}
\hline \multicolumn{2}{|l|}{ Source: Existing maritime app } \\
\hline \multicolumn{2}{|l|}{ 7.01 Enhanced cybersecurity } \\
\hline \multicolumn{2}{|c|}{ Deploy a cybersecurity layer so that it can provide support to the model. Add to periodical drills the ones on cybersecurity } \\
\hline \multicolumn{2}{|c|}{\begin{tabular}{l|l} 
Impacted processes & \\
\end{tabular}} \\
\hline 11.3.1 Define IT Security and Risks Strategy & $\begin{array}{l}\text { The process in itself will not change much, but the resources allocated will now be of } \\
\text { a higher expertise and with the tools to monitor and enable constant improvement. }\end{array}$ \\
\hline 11.3.2 Define IT Resilience Strategy & $\begin{array}{l}\text { The process in itself will not change much, but the resources allocated } \\
\text { will now be of a higher expertise and with the tools to monitor and en- } \\
\text { able constant improvement. }\end{array}$ \\
\hline 11.3.3 Control IT Security and Risks & $\begin{array}{l}\text { The process in itself will not change much, but the resources allocated will now be of a } \\
\text { higher expertise and with the tools to monitor and enable constant improvement. }\end{array}$ \\
\hline \multicolumn{2}{|l|}{ Devil's quadrangle } \\
\hline & 7.01 Enhanced cybersecurity \\
\hline Prerequisites & KPIs \\
\hline $\begin{array}{l}\text { - Identification of critical systems } \\
\text { - Identification of vulnerabilities (The IMO has identified } \\
\text { below systems on board ships as particularly vulnerable: } \\
\text { (1) Bridge systems; (2) Cargo handling and management } \\
\text { systems; (3) Propulsion and machinery management and } \\
\text { power control systems; (4) Access control systems; (5) Pas- } \\
\text { senger servicing and management systems; (6) Passenger } \\
\text { facing public networks; (7) Administrative and crew wel- } \\
\text { fare systems; and (8) Communication systems) } \\
\text { - Cybersecurity experts }\end{array}$ & - Percentage of improvement on cyberattacks prevented \\
\hline
\end{tabular}

Figure A42. Enhanced cybersecurity data sheet.

\begin{tabular}{|l|l|}
\hline \multicolumn{2}{|l|}{ Source: Existing maritime app } \\
\cline { 1 - 2 } 7.02 Cargo documents management \\
\hline Management of cargo documentation (certificates, contracts, transmission, etc.) using blockchain \\
\hline Impacted processes & \\
\hline $\begin{array}{l}\text { 6.1.2 Manage Departure Customs and Rest of De- } \\
\text { parture Paperwork }\end{array}$ & $\begin{array}{l}\text { The activities of this process will change, replacing manual activities with blockchain } \\
\text { ones. }\end{array}$ \\
\hline
\end{tabular}

Figure A43. Cont. 


\begin{tabular}{|l|l|}
\hline $\begin{array}{l}\text { 6.3.1 Manage Arrival Customs and Rest of Arrival } \\
\text { Paperwork }\end{array}$ & $\begin{array}{l}\text { The activities of this process will change, replacing manual activities with } \\
\text { blockchain ones. }\end{array}$ \\
\hline $\begin{array}{l}\text { 8.2.1 Sign Multimodal Transportation Merchant Re- } \\
\text { ception Documents }\end{array}$ & The activities of this process will change, replacing manual activities with blockchain ones. \\
\hline $\begin{array}{l}\text { 8.2.3 Sign Multimodal Transportation Merchant De- } \\
\text { livery Documents }\end{array}$ & The activities of this process will change, replacing manual activities with blockchain ones. \\
\hline Devil's quadrangle & \\
\hline \multicolumn{1}{|l|}{} \\
\hline
\end{tabular}

Figure A43. Cargo documents management data sheet.

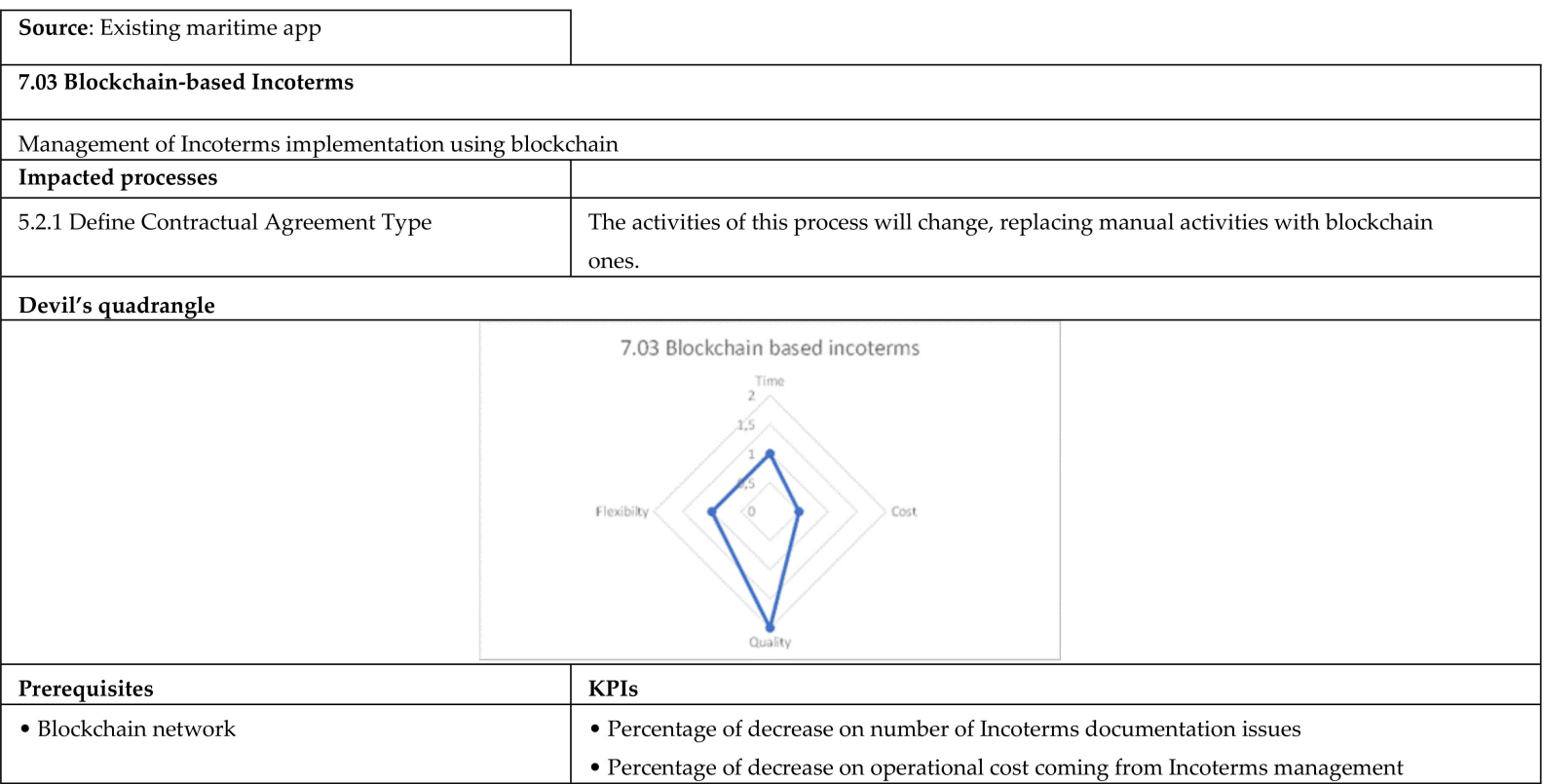

Figure A44. Blockchain-based Incoterms data sheet.

\begin{tabular}{|l|l|}
\hline \multicolumn{2}{|l|}{ Source: Existing maritime app } \\
\cline { 1 - 2 } 7.04 Electronic logbook & \\
\hline Securitized logbooks on board using blockchain (maritime, machine, fuel, ballast water, etc.) \\
\hline Impacted processes & $\begin{array}{l}\text { The process needs to integrate the logbook in its activities, mainly on collecting and re- } \\
\text { porting information from the voyage. }\end{array}$ \\
\hline 6.2.2 Sea Voyage & $\begin{array}{l}\text { The activities within the process should include the certification using this } \\
\text { electronic logbook. }\end{array}$ \\
\hline 13.2.2 Obtain Ship Initial Certificates & The activities within the process should include the certification using this electronic logbook. \\
\hline 13.2.4 Maintain Certificates & \\
\hline Devil's quadrangle &
\end{tabular}

Figure A45. Cont. 


\begin{tabular}{|l|l|}
\hline \multicolumn{1}{|l|}{} & \\
\hline Prerequisites & KPIs \\
\hline - Blockchain network & $\begin{array}{l}\text { Percentage of decrease on number of logbooks documentation issues } \\
\text { P Percentage of reduction of logbooks' data inaccuracy }\end{array}$ \\
\hline
\end{tabular}

Figure A45. Electronic logbook data sheet.

\begin{tabular}{|c|c|}
\hline Source: Existing maritime app & \\
\hline 8.01 Spare parts using 3DP & \\
\hline Development of spare parts for ship's maintenance using 3[ & \\
\hline Impacted processes & \\
\hline $\begin{array}{l}\text { 7.3.1 Plan and Execute Ship Daily Maintenance and Pe- } \\
\text { riodical Crew Exercises }\end{array}$ & $\begin{array}{l}\text { The activities within this process will need to take into account the presence of on- } \\
\text { board infrastructure of } 3 \text { D printers and the ability to produce the most common } \\
\text { ones. }\end{array}$ \\
\hline 10.5.3 Manage Assets Needs and Logistics & $\begin{array}{l}\text { Logistics will be highly impacted, since the need of warehouses or lo- } \\
\text { gistics providers will decrease in favor of the 3DP technology. }\end{array}$ \\
\hline Devil's quadrangle & \\
\hline & 8.01 Spare parts using 3DP \\
\hline Prerequisites & KPIs \\
\hline $\begin{array}{l}\text { - Suppliers specifications for the spare part } \\
\text { - 3DP printer } \\
\text { - Classification Society and Administration approval } \\
\text { (DNV \& Lloyds already on it) }\end{array}$ & $\begin{array}{l}\text { - Percentage of decrease in annual maintenance hours } \\
\text { - Percentage of decrease in spares' errors } \\
\text { - Percentage of improvement on maintenance costs }\end{array}$ \\
\hline
\end{tabular}

Figure A46. Spare parts using 3DP data sheet.

\section{References}

1. United Nations Conference on Trade and Development. Review of Maritime Transport 2021. UNCTAD/RMT/2021. Available online: https://unctad.org/system/files/official-document/rmt2021_en_0.pdf (accessed on 2 February 2022).

2. Gartner Group. Gartner Predicts the Future of Supply Chain Technology. Available online: https://www.gartner.com/ smarterwithgartner/gartner-predicts-the-future-of-supply-chain-technology (accessed on 2 February 2022).

3. Munim, Z.H.; Dushenko, M.; Jaramillo Jimenez, V.; Shakil, M.H.; Imset, M. Big data and artificial intelligence in the maritime industry: A bibliometric review and future research directions. Marit. Policy Manag. 2020, 47, 577-597. [CrossRef]

4. Plaza-Hernández, M.; Gil-González, A.B.; Rodríguez-González, S.; Prieto-Tejedor, J.; Corchado-Rodríguez, J.M. Integration of IoT Technologies in the Maritime Industry. In Proceedings of the International Symposium on Distributed Computing and Artificial Intelligence, L'Aquila, Italy, 16-19 June 2020; Volume 1242. [CrossRef]

5. Kapidani, N.; Bauk, S.; Davidson, I.E. Digitalization in Developing Maritime Business Environments towards Ensuring Sustainability. Sustainability 2020, 12, 9235. [CrossRef]

6. Kapnissis, G.; Leligou, E.-E.; Vaggelas, G. Blockchain Challenges in Maritime Industry: An Empirical Investigation of the Willingness and the Main Drivers of Adoption from the Hellenic Shipping Industry. Open J. Appl. Sci. 2020, 10, 779-790. [CrossRef] 
7. Tijan, E.; Jovic, M.; Aksentijevic, S.; Pucihar, A. Digital transformation in the maritime transport sector. Technol. Forecast. Soc. Change 2021, 170, 120879. [CrossRef]

8. Dumas, M.; La Rosa, M.; Mandling, J.; Reijers, H.A. Introduction to Business Process Management. In Fundamentals of Business Process Management; Springer: Berlin/Heidelberg, Germany, 2013; pp. 1-31.

9. Lyridis, D.V.; Fyrvik, T.; Kapetanis, G.N.; Ventikos, N.; Anaxagorou, P.; Uthaug, E.; Psaraftis, H.N. Optimizing shipping company operations using business process modelling. Marit. Policy Manag. 2006, 32:4, 403-420. [CrossRef]

10. Elbert, R.; Pontow, H.; Benlain, A. The role of inter-organizational information systems in maritime transport chains. Electron. Mark. 2017, 27, 157-173. [CrossRef]

11. Cimino, M.G.C.A.; Palumbo, F.; Vaglini, G.; Ferro, E.; Celandroni, N.; La Rosa, D. Evaluating the impact of smart technologies in harbor's logistics via BPMN modeling and simulation. Inf. Technol. Manag. 2017, 18, 223-239. [CrossRef]

12. Nikitakos, N.; Lambrou, M.A. Chapter 12 Digital Shipping: The Greek Experience. Res. Transp. Econ. 2007, 21, 383-417. [CrossRef]

13. Trkman, P. The critical success factors of business process management. Int. J. Inf. Manag. 2010, 30, 125-134. [CrossRef]

14. American Productivity \& Quality Centre. APQC Process Classification Framework (PCF)—Cross Industry—PDF Version 7.2.1. 2018. Available online: https:/ / www.apqc.org/resource-library/resource-listing/apqc-process-classification-framework-pcfcross-industry-pdf-8 (accessed on 30 January 2020).

15. American Productivity \& Quality Centre. APQC Process Classification Framework (PCF)—Cross Industry—Excel Version 7.2.1. 2019. Available online: https:/ / www.apqc.org/resource-library/resource-listing/apqc-process-classification-framework-pcfcross-industry-excel-7 (accessed on 30 January 2020).

16. Stopford, M. Maritime Economics; Routledge: Oxon, UK, 2009.

17. Song, D.W.; Panayides, P.M. Maritime Logistics; Kogan Page Limited: London, UK, 2015.

18. Tran, N.K.; Haasis, H.-D.; Buer, T. Container shipping route design incorporating the costs of shipping, inland/feeder transport, inventory and CO2 emission. Marit. Econ. Logist. 2016, 19, 667-694. [CrossRef]

19. United Nations Conference on Trade and Development. United Nations Conference on a Convention on International Multimodal Transport. UNCTAD 1981. Available online: https://unctad.org/en/PublicationsLibrary/tdmtconf17_en.pdf (accessed on 30 January 2020).

20. Lawshe, C.H. A quantitative approach to content validation. Pers. Psychol. 1975, 28, 563-575. [CrossRef]

21. Dumas, M.; La Rosa, M.; Mandling, J.; Reijers, H.A. Process Redesign. In Fundamentals of Business Process Management; Springer: Berlin/Heidelberg, Germany, 2013; pp. 253-296. 